Atmos. Chem. Phys. Discuss., doi:10.5194/acp-2016-368, 2016

\title{
Investigating the Impacts of Saharan Dust on Tropical Deep Convection Using Spectral Bin Microphysics, Part 1: Ice Formation and Cloud Properties
}

\author{
Matthew Gibbons ${ }^{1}$, Qilong Min ${ }^{1}$, Jiwen Fan ${ }^{2}$
}

$5{ }^{1}$ Atmospheric Science Research Center, State University of New York, Albany NY 12203, USA

${ }^{2}$ Earth Systems Analysis \& Modeling, Pacific Northwest National Laboratory

Correspondence to: Qilong Min (qmin@albany.edu)

Abstract. To better understand the impacts of dust aerosols on deep convective cloud (DCC) systems revealed by previous observational studies, a case study in the tropical eastern Atlantic was investigated using the Weather Research and

10 Forecasting (WRF) model coupled with a Spectral Bin Microphysics (SBM) model as a two-part study. A detailed set of ice nucleation parameterizations linking ice formation with aerosol particles have been implemented in the SBM for this study. It is found that, dust, transported from the Sahara desert and acting as ice nuclei (IN), increases heterogeneous formation of ice particles at temperatures above $-38^{\circ} \mathrm{C}$ by approximately a factor of four per IN magnitude increase from $0.12 \mathrm{~cm}^{-3}$. Homogeneous ice formation is reduced below $-38^{\circ} \mathrm{C}$ by up to $79 \%$, due to greater conversion of liquid drops to ice at warmer

15 temperatures. The ice particle size distribution (PSD) is shifted towards smaller sizes at heterogeneous temperatures and median sizes at colder temperatures due to increased vapor competition and crystal aggregation. Graupel sizes are reduced due to increased riming of more numerous, but smaller, ice particles. Liquid mass is reduced by up to $85 \%$ at midlevels due to increased riming, drop freezing and Bergeron process evaporation. Despite the enhanced vertical motion in the dust cases (up to $30 \%$ ) , average cloud top height was found to be lowered by up to $3.29 \mathrm{~km}$ in comparison with the background aerosol

20 (Clean) case, which is consistent with observations. This is due to increased sedimentation rates resulting from earlier formation of precipitation sized particles.

\section{Introduction}

Deep convective clouds (DCC) are important sources of precipitation and play a strong role in both regional and global circulation, with tropical convection being particularly significant (Arakawa, 2004). The strong updrafts within convective clouds can transport small cloud particles to the level of neutral buoyancy where they spread out to form the anvil associated with DCC (Folkins, 2002; Mullendore, 2005). The convective intensity controls the depth, area, and lifetime of the resulting anvil clouds (Futyan and Del Genio, 2007). The greater area coverage and lifetime persistence of the anvil cloud makes this type of cloud important to global energy balance and radiative transfer, making the study of deep convective clouds important for current and future climate research (Solomon et al., 2007), especially with regards to the highly uncertain effects of the aerosol indirect effect (AIE) mediated cloud radiative forcing (Rosenfeld et al., 2013). 
Atmos. Chem. Phys. Discuss., doi:10.5194/acp-2016-368, 2016

Manuscript under review for journal Atmos. Chem. Phys.

Chemistry

Published: 18 May 2016

(c) Author(s) 2016. CC-BY 3.0 License.

and Physics

Discussions

(c) (i)

Observational and modeling studies of DCC have shown different results relating to the effect of aerosol on convection and precipitation, indicating that aerosol may either enhance or suppress convection and precipitation depending on aerosol concentration and environmental conditions (Khain and Pokrovsky, 2004 Khain et al., 2004, 2005, 2008; van den Heever et al., 2006; Fan et al., 2007b; Min et al., 2009; Min and Li, 2010; Li and Min, 2010; Min et al., 2014; Altaratz et al., 2014).

5 Clouds forming in elevated aerosol environments exhibit reduced cloud drop effective radii as a result of a greater number of smaller drops forming (Andreae et al., 2004; Koren et al., 2005), which in turn can result in less efficient collisioncoalescence processes (Khain et al., 2005) delaying the formation of precipitation to higher levels in the clouds. Condensation and evaporation processes will be affected by the altered drop size distribution and number concentration, resulting in changes to the location and intensity of latent heat release within the cloud (Khain et al., 2005; Rosenfeld et al.,

10 2008). Increased condensational latent heat release resulting from the greater droplet nucleation can result in stronger convective updrafts leading to the formation of taller and wider clouds (Frederick, 2006; Zhang et al., 2007), while increased evaporation can result in stronger cold pool formation and enhanced secondary convection (Khain 2009, Lee et al., 2010). Aerosol related changes to cloud macrophysics are frequently attributed solely to convective invigoration by the increased cloud condensation nuclei (CCN). However, a study by Fan et al. (2013) involving simulations of DCC in three different

15 regions, suggested that the observed taller and wider clouds are better explained by the changes of CCN to the microphysical properties. Thermodynamic invigoration did not unanimously occur in the study when polluted conditions were simulated, although increased cloud fraction and cloud top height were present. The study noted that the reduced hydrometeor sizes in the polluted case allowed greater cloud mass to be detrained from the convective core, and decreased particle fallout speed that slows down the cloud anvil dissipation.

Earlier studies tend to focus upon the action of soluble aerosols as cloud condensation nuclei (CCN), with changes to ice formation resulting from the affected liquid processes only (Rosenfeld, 2000). However, DCC can also be sensitive to the aerosols that act as ice nuclei (IN) (Tao et al., 2007). Ice formation in deep convective clouds may result from heterogeneous and homogeneous ice nucleation depending on the depth of the cloud and the chemical composition of the background aerosols. Heterogeneous ice nucleation can occur at temperatures between $0^{\circ} \mathrm{C}$ and $-38^{\circ} \mathrm{C}$ via the mechanisms of condensation/deposition, immersion, and contact freezing (Tao et al., 2012; Altaratz et al., 2014; Hiron \& Flossman, 2015) when ice nuclei (IN) are present. Homogeneous ice nucleation involves droplet and aerosol haze particle freezing at temperatures lower than $-38^{\circ} \mathrm{C}$. Deep convection frequently shoots liquid drops up to the upper troposphere where the temperature is colder than $-38^{\circ} \mathrm{C}$, leading to strong homogenous droplet freezing.

Dust aerosols have been observed at significant concentrations even in remote locations far from their expected source regions (Prospero, 1999) and are predominately composed of insoluble silicate particles (Lohmann, 2002) which have been established to act as effective IN (Pruppacher and Klett, 1997; Demott et al., 2003; Sassen et al., 2003). The Saharan Air Layer (SAL; Prospero and Carlson, 1970; Carlson and Prospero, 1972) is an elevated layer of dry air between 850-500 hPa, 
Atmos. Chem. Phys. Discuss., doi:10.5194/acp-2016-368, 2016

Manuscript under review for journal Atmos. Chem. Phys.

Chemistry

Published: 18 May 2016

(c) Author(s) 2016. CC-BY 3.0 License.

often containing lofted dust particles. The SAL has been observed interacting with tropical cloud systems, such as tropical cyclones and mesoscale convective systems (MCS), and may impact their intensity and evolution (Karyampudi and Carlson, 1988; Dunion and Velden, 2004; Min et al., 2009). Ekman et al. (2007) studied the sensitivity of a continental storm to IN concentration and found that updrafts were enhanced due to added latent heat release from ice crystal depositional growth.

5 The stronger updrafts enhanced homogeneous nucleation, increasing anvil cloud coverage and precipitation. Fan et al. (2010) compared the effects of CCN and IN on convection and precipitation and noted that the CCN effect is more evident in changing cloud anvil size, lifetime, and microphysical properties. IN was shown to have a small effect on convective strength, but the microphysical effects could still be significant. Note Fan et al. (2010) did not have a prognostic IN treatment as what we have done for this study.

10

A trans-Atlantic dust outbreak of Saharan origin occurring 1-10 March 2004 (Morris et al., 2006) was subjected to a rigorous multi-sensor and multi-platform observational analysis (Min et al., 2009; Li et al., 2010; Min and Li, 2010; Li and Min, 2010; Min et al.,2014). The interaction of this dust outbreak with developing DCC systems resulted in strong effects on cloud microphysical processes. The effects of dust resulted in changes to the vertical precipitation structures, in which the

15 size spectrum was shifted from heavy to light precipitation or suppressed entirely (Min et al., 2009; Li and Min, 2010). These microphysical changes can alter the vertical heating structure in both the convective and stratiform regions, possibly creating strong cloud thermodynamical feedbacks (Rosenfeld et al., 2008). When cloud dynamics and thermodynamics are strictly constrained, the effects of dust on warm cloud processes are strongly dependent on cloud top height and precipitation regime, indicating that vertical transport is important to aerosol-cloud interactions (Li et al., 2010). It was also found that

20 substantial changes to cloud top distributions resulted from a change in the partition of homogeneous and heterogeneous ice processes under dusty conditions, with such macrophysical changes in the cloud systems resulting in substantial thermal infrared radiation cooling of up to $16 \mathrm{Wm}^{-2}$ (Min and $\mathrm{Li}, 2010$ ). In this study, we will focus on how dust in SAL impacts ice cloud microphysical processes in DCC and the resulting change to cloud macrophysical and precipitation properties. Convective invigoration has been observed under dusty conditions, which can enhance water vapor supply in precipitating

25 DCC and lift ice particles to higher altitudes. These microphysical effects in concert with large scale dynamics and thermodynamics influence macrophysics of DCC and associated precipitation. (Min et al., 2014).

The quantification of aerosol-cloud interactions in numerical modeling studies remains a challenge. Aerosols influence the character of individual clouds and storms, but evidence of a systematic effect on storm or precipitation intensity is still

30 limited and ambiguous. The representation of processes relevant to aerosol-cloud interactions is still considered weak, due to the some of the fundamental details of cloud microphysical processes being poorly understood, particularly with regards to ice and mixed-phase clouds (Boucher et al., 2013). This low confidence is a result of the complex coupling between the processes controlling cloud and precipitation properties, which cover a wide range of spatial and temporal scales (Tao et al., 2012). To gain better insight into mixed-phase cloud and precipitation processes, numerical models must include a detailed 
Atmos. Chem. Phys. Discuss., doi:10.5194/acp-2016-368, 2016

handling of ice microphysical processes that connect ice formation to the presence of ice nuclei, such as atmospheric dust. The study of Halder at al. (2015) tested the sensitivity of severe thunderstorms to different bulk microphysics and found the best agreement with observations occurred when aerosol-based heterogeneous ice formation was added to the most detailed bulk microphysics scheme.

By selecting bin microphysics rather than bulk microphysics, it is possible to explicitly solve the relevant microphysical equations without making a priori assumptions about the particle size distribution (PSD) of the resulting hydrometeors or modifying the scheme to simulate different atmospheric phenomena from tropical to polar environments (Khain et al., 2015). Unlike a bulk microphysics scheme, in which the PSD of every predicted hydrometeor type has a predefined shape, bin 10 microphysics schemes allow PSDs to evolve naturally in conjunction with in-cloud and large scale processes. To take advantage of this greater accuracy, we have selected the Hebrew University Cloud Model (HUCM) Spectral Bin Microphysical (SBM; Khain et al., 2004; Khain et al., 2009; Fan et al., 2012a) for use in our study.

As dust aerosols are widely known to affect heterogeneous ice formation, accurate simulations of ice formation processes in

15 DCC require ice nucleation to be directly linked with aerosol concentration. In this study, we have added a set of ice nucleation parameterizations to the WRF-SBM to examine how dust acting as IN impacts cloud properties and precipitation. Heterogeneous formation of ice resulting from immersion, contact, and deposition-condensation freezing schemes have been updated to account for the presence of dust in our case study. These updates follow the implementation first suggested in Gong et al. (2010), with additional schemes and updates incorporated from Fan et al. (2014). Specific updates made to the

20 model have been outlined in section 2 . The broad coverage provided by these multiple ice formation schemes in conjunction with the detailed handling of cloud liquid and ice microphysics offered by the WRF-SBM gives our study a unique insight into the topic of dust aerosol-DCC interactions. To assess the agreement of the model with observations, we have simulated a MCS occurring on 08 March 2004 in the tropical eastern Atlantic under the influence of a Saharan dust outbreak (Morris et al. 2006; Min et al. 2009). The results of our study have been presented as two parts. The first part, introduced in this paper, outlines the changes made by our group to the WRF-SBM coupled model and includes an overview of the results pertaining to the effects of dust on ice formation and resulting cloud properties. The second part will focus on the resulting changes to the precipitation fields under dusty conditions.

\section{Model Description}

Numerical simulations were undertaken using the WRF version 3.1.1 developed by the National Center for Atmospheric 30 Research (NCAR) as described in Skamarock et al. (2008). WRF solves the fully compressible, non-hydrostatic Euler equations formulated on terrain following hydrostatic-pressure coordinates and the Arakawa C-grid. The model uses RungeKutta second- to sixth-order advection schemes in both horizontal and vertical directions. The fifth-order advection scheme 
Atmos. Chem. Phys. Discuss., doi:10.5194/acp-2016-368, 2016

is used in this study. The monotonic technique is employed for advection of scalar and moist variables. The cloud microphysical scheme is described below.

\subsection{Spectral Bin Microphysics (SBM)}

The original SBM (Khain et al., 2004) solves a system of kinetic equations for the size distribution functions for 7

5 hydrometeor types: water droplets, ice crystals (plate, column, and dendrite), aggregates, graupel, and frozen drops/hail. An 8th size distribution function exists for $\mathrm{CCN}$. Each size distribution is represented by 33 mass doubling bins, where the mass of a particle in each bin is twice the mass of a particle in the preceding bin. A fast version of the SBM (Fast-SBM) with four size distributions of water drops, low density ice (ice crystals and aggregates), high density ice (graupel and hail), was created in order to substantially reduce the computational costs (Khain et al. 2009, Fan et al 2012). Further details about the mechanics of the SBM can be found in Khain et al. (2004) and Fan et al. (2012) and will not be repeated here.

In order to examine IN impacts on clouds and precipitation, an additional prognostic variable for IN particle (dust in this case) concentration was added to represent the sink by ice nucleation and sources of dust (from lateral boundaries). In this study, due to the presence of a dust layer in the observed case, such a layer has been added. The dust in the layer can serve as

15 IN, CCN, or some fractional combination of the two can be set by the user. This allows us to test the sensitivity of clouds within our model to such a mixture of nuclei. In this study, we primarily consider the dust effects by acting as IN, but also have run a preliminary sensitivity study allowing some dust to act as CCN in addition to IN.

\subsection{Ice Formation Parameterizations}

The original SBM (Khain et al. 2004) included both homogeneous and heterogeneous ice formation, although without directly connecting ice formation to a prognostic IN variable. Liquid drop freezing for both homogeneous and immersion mechanisms was provided by Bigg (1953). Ice formation resulting from condensation and deposition freezing was provided by Meyers et al. (1992). Contact freezing is not included in the original SBM. In order to perform a study of aerosol impacts on heterogeneous ice formation, it is necessary to directly link ice nucleation rates to aerosol properties. The study of Gong et al. (2010), and more recently Fan et al. (2014), updated the available homogeneous freezing mechanisms and additionally implemented separate parameterizations into the SBM for depositional, contact and immersion freezing, with ice formation in each of these schemes directly linked to the prognostic IN variable. This implementation also tracks the individual contribution of each heterogeneous and homogeneous freezing mechanism to the total ice formation, allowing for these contributions to be compared under different dust loading conditions. To take advantage of this unique and comprehensive set of ice formation parameterizations, we have adopted and expanded upon the Gong et al. (2010) homogeneous and heterogeneous ice formation mechanisms into our current study, with available schemes outlined below. 
Atmos. Chem. Phys. Discuss., doi:10.5194/acp-2016-368, 2016

Atmospheric

Manuscript under review for journal Atmos. Chem. Phys.

Chemistry

Published: 18 May 2016

(c) Author(s) 2016. CC-BY 3.0 License.

and Physics

Discussions

(c) (i)

\subsubsection{Homogeneous Ice Nucleation and Freezing Schemes}

The new ice formation implementation allows the user to select between three available pure drop freezing schemes. We maintain the parameterization of Bigg (1953), included in the original SBM code, to serve as a benchmark for homogeneous pure drop freezing. We have also incorporated the parameterization of Heymsfield and Milosevich (1993), implemented in

5 Gong et al. (2010), and a simple (temperature threshold only) based freezing scheme $\left(\mathrm{H}_{\text {thr }}\right)$ to provide alternate methods of homogeneous pure drop freezing. The $\mathrm{H}_{\mathrm{thr}}$ threshold based scheme automatically freezes all liquid drops that reach the $-38^{\circ} \mathrm{C}$ homogeneous freezing threshold temperature, irrespective of drop size, under the assumption that liquid drops are rare under these conditions. These alternate methods can be used to replace the original Bigg (1953) parameterization in the simulation, in order to study the differences between the original stochastic (Bigg) and the newer temperature and/or drop-volume

10 (Heymsfield and Milosevich; $\mathrm{H}_{\text {thr }}$ ) based freezing rates. The current results use the $\mathrm{H}_{\text {thr }}$ threshold based scheme to provide pure drop freezing.

We also include the aerosol freezing parameterization of Liu and Penner (2005), following the implementation used by Gong et al. (2010), allowing for cirrus cloud formation to be studied. This parameterization calculates the homogeneous ice

15 nucleation of aerosols coated by sulfate, while also including depositional nucleation as originally described by Meyers et al. (1992). In addition to the pure sulfate aerosol number concentration, the scheme includes the effects of updraft velocity (w) and temperature under a critical relative humidity threshold with respect to water when calculating new ice formation.

\subsubsection{Heterogenous Ice Nucleation and Freezing Schemes}

Depositional/condensational freezing in the model were originally provided by the Meyers et al. (1992) parameterization. It

20 is a supersaturation dependent parameterization. Deposition nucleation should be important for deep convection, but there is no such a scheme developed for deep convection with a connection with aerosols. As noted in Meyers et al. (1992) it is difficult to distinguish the relative contributions of depositional and condensational freezing in a parcel, since both form similarly sized small ice crystals, despite the different mechanisms of vapor to ice in the former and condensation followed immediately by freezing in the latter case. However, studies suggest that small ice formed in the temperature range covered by this scheme can have a large impact on subsequent ice formation at higher altitudes (Ackerman et al. 2015; Hiron and Flossman, 2015; Lawson et al., 2015).To link depositional/condensational freezing with aerosols, we follow the implementation of van den Heever et al. (2006), updated from the Meyers et al. (1992) version. The number of ice crystals generated by depositional-condensational nucleation $\left(\mathrm{N}_{\mathrm{hen}}\right)$ is proportional to the IN number concentration $\left(\mathrm{N}_{\mathrm{IN}} ; 1^{-1}\right)$ by Eq. (1):

30

$N_{\text {hen }}=N_{I N} F_{M}$, 
Atmos. Chem. Phys. Discuss., doi:10.5194/acp-2016-368, 2016

Manuscript under review for journal Atmos. Chem. Phys.

where $\mathrm{F}_{\mathrm{M}}$ (unitless) is the function of the depositional-condensational nucleation by Meyers et al. (1992) that represents the fraction of available IN (Nid; $1^{-1}$ ) as calculated in Eq. (2):

$N_{i d}=\exp \left\{-6.39+0.1296\left[100\left(S_{i}-1\right)\right]\right\}$,

with $S_{i}$ being the saturation over ice. The value of $F_{M}$ is equal to 1 for conditions at ice supersaturation of $40 \%$, at which point all IN are activated, and is equal to 0 when supersaturation over ice is negative. The initial size of an ice crystal formed by this scheme is assumed to be $2.5 \mu \mathrm{m}$ in radius and is assigned to the smallest ice size bin.

10 As stated above, the immersion freezing in the original scheme uses the parameterization of Bigg (1953), which is temperature-dependent only. To provide an aerosol-based immersion freezing scheme, we have incorporated the parameterization of DeMott et al. (2015), which was implemented by Fan et al. (2014) (cited as DeMott et al. (2013) in Fan et al. (2014) due to DeMott et al. (2015) not yet being published). The DeMott et al. (2015) immersion freezing rate is parameterized as in Eq. (3):

15

$$
N_{i m}=(C F)\left(N_{I N}\right)\left(\alpha\left[273.16-T_{k}\right]+\beta\right) \exp \left(\gamma\left[273.16-T_{k}\right]+\delta\right),
$$

$\mathrm{CF}$ is an instrumental correction factor with a value of 3. Coefficients $\alpha, \beta, \gamma$, and $\delta$ are 5.95E-5, 1.25, 0.46, and -11.6, respectively, representing mineral dust particles (Demott et al., 2015) $\mathrm{T}_{\mathrm{k}}$ is the cloud temperature in degrees Kelvin, $\mathrm{N}_{\mathrm{IN}}$ is

20 the number concentration of total aerosol particles with diameter larger than $0.5 \mu \mathrm{m}$, and $\mathrm{N}_{\mathrm{im}}$ is the maximum number of immersion ice possible in the given temperature range. Liquid drops are consumed over the size spectrum starting with the largest sizes down to the smallest until the minimum of $\mathrm{N}_{\mathrm{im}}$ or drop number is reached. According to Yin et al. (2005), drops with a radius smaller than $79.37 \mu \mathrm{m}$ will be frozen to pristine ice crystals, otherwise graupel is formed.

25 We have also adopted the contact freezing parameterization of Muhlbauer and Lohmann (2009), which is based on Cotton (1986) and Young (1977). In this parameterization, contact freezing is a result of the collision of supercooled liquid water drops and IN due to Brownian motion. The contact freezing rate is therefore proportional to the drops' radius and number concentration. It is also proportional to the IN number concentration and Brownian diffusivity in air. Unlike Muhlbauer and Lohmann (2009) who calculated the freezing rate for the sum of all drops, we perform the calculation in this study for each

30 spectral bin of drops. Then, the contact freezing rate $\left(\mathrm{N}_{\mathrm{CNT}} ; 1^{-1} \mathrm{~s}^{-1}\right)$ for each individual size bin is represented by Eq. (4):

$N_{C N T}=4 \pi r_{c} N_{c} D_{k} N_{I N}$, 
Atmos. Chem. Phys. Discuss., doi:10.5194/acp-2016-368, 2016

Manuscript under review for journal Atmos. Chem. Phys.

Published: 18 May 2016

(C) Author(s) 2016. CC-BY 3.0 License.

(c) (i)
Atmospheric

Chemistry

and Physics

Discussions

where $r_{C}(m)$ and $N_{C}(m-3)$ is radius and number concentration of drops respectively. $D_{k}$ is the dust aerosol Brownian diffusivity (m2s-1), and is parameterized by Eq. (5):

$D_{k}=\frac{k_{B} T C}{6 \pi \eta r}$

5

$D_{k}$ is a function of the Boltzmann constant $K_{B}=1.28 \times 10^{-23} \mathrm{~m}^{2} \mathrm{~kg} \mathrm{~s}^{-2} \mathrm{~K}^{-1}, \mathrm{~T}$ is the air temperature, $\mathrm{r}$ is the dry dust aerosol median radius, $\eta$ is the viscosity of air and $C$ is the Cunningham slip correction factor. The viscosity of air depends on temperature, as calculated by Eq. (6):

$10 \eta=10^{-5}\left[1.718+4.9 \times 10^{-3}(T-273.15)-1.2 \times 10^{-23}(T-273.15)^{2}\right]$,

The Cunningham slip correction factor is calculated by Eq. (7):

$C=1+1.26 \frac{\lambda}{r} \frac{1013.25}{p} \frac{T}{273.15}$

15

with the molecular mean free path length of air $\lambda=0.066 \mu \mathrm{m}$, and $\mathrm{p}$ is the pressure. To simplify the calculation, the contact freezing number is the available dust number concentration $\mathrm{N}_{\mathrm{IN}}$, with freezing efficiency of 1 . Upon freezing, drops with a radius smaller than $79.37 \mu \mathrm{m}$ will be frozen to pristine ice crystals, larger drops will be frozen as graupel.

20 It should be noted that currently there is no ice nucleation parameterizations specifically developed for DCC, and the understanding of ice nucleation for DCC is still very limited. The most recent ice nucleation parameterization of DeMott et al. (2015) in conjunction with the previously stated parameterizations have been used in this study to gain the understanding of dust aerosol impact on DCC by serving as IN and the relative contribution of each mechanism to the total ice formation.

\section{Experiment Design}

25 For our study, we have conducted experiments simulating the 08 March 2004 MCS described in Min et al. (2009), using realistic initial and boundary conditions. Four one-way nested domains were used, with horizontal grid resolutions of $81 \mathrm{~km}$, $27 \mathrm{~km}, 9 \mathrm{~km}$, and $3 \mathrm{~km}$ respectively and 41 vertical levels in each domain. The numbers of horizontal grid points in each domain are $81 \times 81,81 \times 81,81 \times 81$, and 150x150, respectively. Initial and boundary conditions for the first domain are provided by the $1^{\circ} \mathrm{x} 1^{\circ}$ 6-hourly National Centers for Environmental Prediction (NCEP) global final analysis dataset, with

30 initial conditions for the other three domains being interpolated from the first domain. Due to the SBM not being designed to run at coarse resolutions, the SBM provides microphysics for only the $3 \mathrm{~km}$ resolution domain with bulk microphysics being 
Atmos. Chem. Phys. Discuss., doi:10.5194/acp-2016-368, 2016

Atmospheric

Chemistry

Published: 18 May 2016

(c) Author(s) 2016. CC-BY 3.0 License.

and Physics

Discussions

(c) (i)

selected for domains 1-3. The specific WRF parameterizations selected for the experiments are detailed in Table 1. Figure 1 provides the locations of these four domains, displaying the Atmospheric Infrared Sounder (AIRS) retrieval (Fig. 1a) and the model derived precipitable water averaged over the duration of the simulation (Fig. 1b). The large scale patterns are well reproduced by the model, assuring that meteorological conditions in the region of interest are being represented correctly.

The initial number concentrations of $\mathrm{CCN}$ are kept identical between the different cases. Typical marine aerosol number concentrations tend to be low, on the order of 300-600 $\mathrm{cm}^{-3}$ (O'Dowd et al., 1997; Yoon et al., 2007). Therefore, the CCN number is set to a uniform value of $300 \mathrm{~cm}^{-3}$ below $2 \mathrm{~km}$ with the $\mathrm{CCN}$ number being reduced exponentially from this value as height increases above $2 \mathrm{~km}$. The initial IN distribution is set to be vertically uniform at $.01 \mathrm{~cm}^{-3}$ for the Clean case. The

10 dust cases add an increasing number of IN to the Clean case's background value in a layer located vertically between $1 \mathrm{~km}$ and $3 \mathrm{~km}$, as observed by Min et al (2009). The dust cases are set with different IN numbers within the dust layer of $0.12 \mathrm{~cm}^{-3}$ (case D.12), $1.2 \mathrm{~cm}^{-3}$ (case D.12), and $12 \mathrm{~cm}^{-3}$ (case D12), respectively. These values were selected based on aerosol measurements that were taken during the trans-Atlantic Aerosol and Ocean Science Expeditions (AEROSE) experiment (Morris et al., 2006) for dates coinciding with the observational study of the March 2004 dust outbreak detailed in Min et al.

15 (2009). The dust loading was assumed to be the difference in the aerosol number of the dusty and pristine periods. Only aerosol particles with a radius greater than 0.5 microns were considered when taking this difference, due to the smaller aerosol sizes being more prevalent during the pristine period compared to the dusty period; a size range also consistent with the study of DeMott et al. (2015) for ice nucleating particles. This resulting dust number was multiplied by an activation fraction suggested by Niemand et al. (2012) for Saharan dust to arrive at the number used for case D.12. Other studies have

20 suggested that dust related IN numbers greater than $1.0 \mathrm{~cm}^{-3}$ are possible (DeMott et al., 2003; Sassen et al., 2003), so two additional dust cases with IN numbers one (D1.2) and two (D12) orders of magnitude greater than the initial D.12 case were included in the study. To prevent the CCN and IN fields from being diluted due to the inflow of air from the lateral boundaries, the CCN and IN numbers of the outer five grid cells (i.e., the boundary points) on each side of domain 4 are set to the initial values throughout the integration period. The initial vertical profile of domain averaged relative humidity shows moist $(>60 \% \mathrm{RH})$ air below $6 \mathrm{~km}$ and drier air $(<50 \% \mathrm{RH})$ above $6 \mathrm{~km}$, while the profiles of horizontal winds evidence weak $(<5 \mathrm{~m} / \mathrm{s})$ to relatively weak $(<10 \mathrm{~m} / \mathrm{s})$ wind shear below $7 \mathrm{~km}$, following the criteria used by Fan et al. (2009b).

Additional criteria used to select subsets of the data for the purpose of our analysis are as follows. Cloudiness within an individual 3D grid cell was determined by the sum of all condensates within it exceeding a $10^{-6} \mathrm{~kg} / \mathrm{kg}$ threshold value, 30 following the definition used in Fan et al. (2013). Cloud top was determined, from the top level of the model down to the surface, as the highest level with at least two consecutive levels exceeding the cloudiness threshold, which was intended to limit the influence of very thin clouds on the resulting analysis. To sort results by precipitation regime, we adapt the definitions of Houze (1994) for convective and stratiform precipitation, with each vertical column classified as a single precipitation type only. For all precipitating clouds, surface rain rates must exceed $0.05 \mathrm{~mm} / \mathrm{hr}$. Convective precipitation is 
Atmos. Chem. Phys. Discuss., doi:10.5194/acp-2016-368, 2016

Atmospheric

Chemistry

Manuscript under review for journal Atmos. Chem. Phys.

Published: 18 May 2016

(c) Author(s) 2016. CC-BY 3.0 License.

and Physics

Discussions

(c) $\underset{\mathrm{BY}}{\mathrm{B}}$

classified as precipitating column with vertical motion exceeding a $1 \mathrm{~m} / \mathrm{s}$ threshold and cloud thickness of $8 \mathrm{~km}$ or greater. Non-convective precipitating columns are classified as stratiform by the presence of ice-phase precipitation in the column. Precipitating columns with cloud top temperatures warmer than freezing are classified as rain producing warm clouds.

\section{Results}

\section{$5 \quad 4.1$ Cloud Geometry and Vertical Motion}

The study of Min et al. (2009) found the evidence of dusty conditions increasing the frequency of deep clouds with large ice water path, hypothesizing that the action of dust as IN served to increase convective activity due to heterogeneous ice formation increasing latent heat release. To provide an initial comparison with these results, Fig. 2 depicts a vertical crosssection of a specific convective core and its associated stratiform/anvil cloud at a single model time step from the Clean and

10 D1.2 cases. The grey dashed line in Fig. 2a-2d depict the threshold value of cloudiness suggested by Fan et al. (2013) and shows the change to cloud geometry directly. The Clean case (Fig. 1a) shows the classic DCC cloud structure of convective core and associated stratiform region transitioning into the anvil. The D1.2 case also possesses a similar cloud structure, but with a far smaller anvil cloud, which can be a result of either dynamical or microphysical changes. The change in total water content (TWC) in Fig. 2a and Fig. 2b and total (ice and liquid) rain rate in Fig. 2c and Fig. 2d are consistent with the findings

15 of Min et al. (2009). The higher $0^{\circ} \mathrm{C}$ to $-38^{\circ} \mathrm{C}$ TWC is accompanied by a correspondingly larger area of strong vertical motion as outlined by the black solid $(>1 \mathrm{~m} / \mathrm{s})$ and dashed blue $(<-0.5 \mathrm{~m} / \mathrm{s})$ contour lines. This supports the evidence of convective invigoration in dust affected deep, high-IWP clouds. The elevated upper level rain rates are also consistent with the higher upper level reflectivity reported by Min et al. (2009) and Li and Min (2010) for dusty conditions. Despite the higher vertical motion evident in the D1.2 case, the total cloud mass transported into the anvil region is reduced and stratiform height is lowered. The occurrence of higher rain tops and narrower anvils in conditions of higher SST values (stronger dynamical environments) was observed using CloudSat data in the study of Igel et al. (2014). Although higher cloud tops were also reported under these conditions, this demonstrates that similar effects on anvil width can also result from favorable dynamical conditions. However, the convective cores presented in Fig. 2 are nearly identically located geospatially, occur at the same model time, and possess nearly identical SST values below the cores, limiting the dynamical effects on the clouds in this instance.

The presence of higher vertical motion and lowered cloud top height depicted in Fig. 2 for a single convective cloud system supports the hypothesis of Min et al. (2009) that the addition of dust into the environment affects the balance between dynamics and microphysics that results in the observed cloud fields. The study of Min and Li (2010), expanded upon these findings, reporting both a positive correlation between cloud water path and cloud top height and a negative correlation between cloud top height and dust AOD. This provides further support for the hypothesis that the results from the dusty region were not strictly a result of dynamical effects. To ensure the effects depicted in Fig. 2 are not isolated to individual 
Atmos. Chem. Phys. Discuss., doi:10.5194/acp-2016-368, 2016

Atmospheric

Manuscript under review for journal Atmos. Chem. Phys.

Chemistry

Published: 18 May 2016

(c) Author(s) 2016. CC-BY 3.0 License.

and Physics

Discussions

(c) (i)

cloud life stages or some other background condition, Fig. 3 details changes to CTH and vertical motion in the three dust cases compared to the Clean case. Figures $3 \mathrm{a}-3 \mathrm{~d}$ track the percentage of cloud tops reaching the specified height. The Clean case time series (Fig. 3a) tracks the progression from shallow convection to deep convection after the initial 6 hour spin up time, showing the transition through the growth, mature, and decaying stages of the cloud system. In general, the simulation can be separated into periods of strong (hour 10-20) and weaker (hour 21+) convection. The difference plots of Fig. 3b-3d depict a progressive lowering of the cloud field, despite the corresponding maximum updraft speed generally increasing with higher dust numbers (Fig. 3f-3h). However the specific change in CTH differs in the strong and weak convection periods. The relative changes of average CTH in the dust cases during the strong convection period are: $-0.23 \mathrm{~km}(-2.0 \%$; D.12), $0.85 \mathrm{~km}$ (-7.2\%; D1.2), and -1.4 km (-11.7\%; D12). The corresponding changes in updraft speed for this period are: $+0.7 \mathrm{~m} / \mathrm{s}$

10 (+4.8\%; D.12), $+1.5 \mathrm{~m} / \mathrm{s}(+10.1 \%$; D1.2), and $+4.4 \mathrm{~m} / \mathrm{s}(+29.8 \%$; D12). The changes to CTH in the weaker convection period are also in line with our expectations. The relative changes of average $\mathrm{CTH}$ in the dust cases during the weak convection period are: $-0.71 \mathrm{~km}(-5.4 \%$; D.12), $-1.77 \mathrm{~km}(-13.3 \%$; D1.2), and -3.29 km (-24.7\%; D12). The corresponding changes in updraft speed for this period are: $-0.6 \mathrm{~m} / \mathrm{s}$ (-6.3\%; D.12), $-1.3 \mathrm{~m} / \mathrm{s}(-14.2 \%$; D1.2), and $+1.6 \mathrm{~m} / \mathrm{s}(+16.8 \%$; D12). The generally weaker updrafts during this period limit new ice formation which reduces the contribution of latent heating to

15 parcel buoyancy. To illustrate this, we note the similar heterogeneous ice number and updraft changes in the D1.2 (strong convection) and D12 (weak convection) cases. The percent change of downdraft strength in the three dust cases for the strong (weak) convective period are: $-3.6 \%(-3.3 \%),+21.1 \%(-4.02 \%)$, and $+65.4 \%(+26.6 \%)$. The changes in downdraft strength are consistent with the corresponding changes to updraft strength during each convective period. A comparison between these values and changes to ice number concentration is presented in Table 3. The profile of updraft grid points

$20(>1 \mathrm{~m} / \mathrm{s})$ in Fig. 3e further emphasizes that strong updrafts become more common in the dust cases in the locations conducive to heterogeneous ice formation. Near $6 \mathrm{~km}$, the updraft grid point number increases $+13.5 \%$ (D.12), $+34.8 \%$ (D1.2), and $+50.9 \%$ (D12). The enhanced heterogeneous nucleation results in lower cloud tops overall. This contrasts with cases where the enhanced CCN concentrations lead to higher and broader clouds regardless of changes to convective intensity (Devasthale et al. 2005; Li et al 2011; Fan et al., 2013).

\section{$25 \quad 4.2$ Hydrometeor Concentration and PSD}

Both IN concentration and convection strength influence the location of hydrometeor formation, hydrometeor concentration, and subsequently the hydrometeor vertical distribution. Fig. 4 tracks the time evolution of the number concentration of ice/snow crystals (Fig. 4a-4d), cloud/rain drops (Fig. 4f-4h), and graupel (Fig. 4i-4l) averaged over the convective regimes. In the Clean case, most ice particles are located in the homogeneous nucleation regime above the $-38^{\circ} \mathrm{C}$ isotherm, as

30 expected. In the dust cases, shown in the difference plots in Fig. 4b-4d, ice crystal concentrations are increased between the freezing level and the $-38^{\circ} \mathrm{C}$ isotherm due to the more active heterogeneous nucleation processes. The stronger convection period yields higher numbers due to stronger updrafts increasing IN activation and/or transporting more and/or heavier liquid drops into temperatures more favorable for freezing. Increasing the IN concentrations results in higher ice concentrations in 
Atmos. Chem. Phys. Discuss., doi:10.5194/acp-2016-368, 2016

Manuscript under review for journal Atmos. Chem. Phys.

the heterogeneous nucleation regime by approximately a factor of four per magnitude IN increase in the dust cases. The domain average total ice number concentration in the heterogeneous regime during the strong convection period for the primary cases are: $3.1 \mathrm{~L}^{-1}$ (Clean), $4.8 \mathrm{~L}^{-1}$ (D.12), $18.3 \mathrm{~L}^{-1}$ (D1.2), and $86.1 \mathrm{~L}^{-1}$ (D12). The same average during the weak

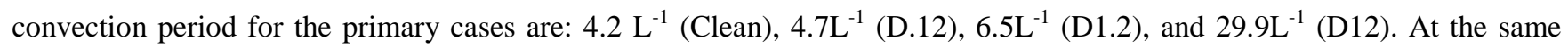

5 time, ice crystal concentrations above or near the $-38^{\circ} \mathrm{C}$ isotherm are substantially reduced: $256.1 \mathrm{~L}^{-1}$ (Clean), $217.8 \mathrm{~L}^{-1}$ (D.12), 68.5 $\mathrm{L}^{-1}$ (D1.2), and 55.7 $\mathrm{L}^{-1}$ (D12). In the weaker convection regime, between hour 21 and 30, this reduction is more

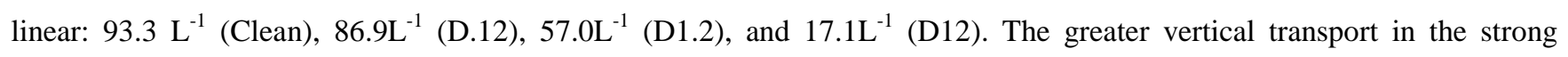
convection period helps explain the similar upper ice number concentrations between the D1.2 and D12 case. A comparison between the ice number concentration, vertical motion, and CTH for the two convective periods is provided in Table 3.

10 Changes in liquid drop and graupel number have also been provided in Table 3 for the heterogeneous temperature range. Graupel formation is enhanced compared to the Clean case, with graupel number in the Dust cases increasing proportionally with IN concentrations by approximately a factor of three per unit magnitude increase from the D.12 case. The increase of graupel number also occurs at higher levels in the atmosphere compared to the Clean case, with maximum height occurring during the strongest convection. There is a progressive loss of liquid drops at heterogeneous freezing temperatures in the

15 dust cases. The reduction is approximately $30 \%$ per unit magnitude IN increase during both the strong and weak convective periods. Coupled with the similarly progressive increase in graupel number, the loss of liquid drops suggests that fewer drops are reaching the $-38^{\circ} \mathrm{C}$ temperature range to freeze homogeneously in the Dust cases due to the heterogeneous freezing resulting in a much greater conversion of liquid to ice. As activation numbers for the individual ice formation schemes are tracked by the model, we will verify this reduction in a subsequent figure and table. The profound loss of liquid mass

20 following initial ice formation at temperatures warmer than $-10^{\circ} \mathrm{C}$ is similar to the rapid glaciation observed in strong updrafts in the study of Lawson et al. (2015), which was suggested to occur due to the cascading formation of small crystals from drop freezing ice multiplication processes and subsequent riming.

The SBM allows us to examine the effects of dust on the PSD of the different hydrometeors without creating an arbitrary

25 distinction between cloud and precipitation sizes particles. Dust related changes to the bin PSD of each hydrometeor type are described in Fig. 5 and Fig. 6. The provided radii values of the represented hydrometeor species are taken from the precalculated bin radii values used by the model, which are based on assumed particle densities and the mass doubling relationship between the individual bins. For convenience, if a single bin can represent multiple radii, for example, due to a dependence on crystalline habit or aggregation in the ice and snow bin distribution, a mean value for radius is used in the

30 figure. Contour values represent $\log 10$ values of bin population which are scaled by adding 10 to all values. This has been done to improve readability of the contours and allow for difference plots to be constructed with less ambiguity. In this case, a contour of ' 1 ' is equivalent to a ' -9 ' $\log 10$ value. The difference plots likewise describe the relative change of these $\log 10$ values. As dust in our study acts as IN with a minimal impact on liquid nucleation, we focus our discussion on the $0^{\circ} \mathrm{C}$ to $38^{\circ} \mathrm{C}$ degree range conducive to heterogeneous nucleation and freezing. 
Atmos. Chem. Phys. Discuss., doi:10.5194/acp-2016-368, 2016

Manuscript under review for journal Atmos. Chem. Phys.

Figures 5a, 5e, and 5i display time series of PSD averaged over convective data within the selected temperature range for ice/snow, cloud/rain drops, and graupel. The rest of Fig. 5 shows the differences between three Dust cases and the Clean case. The addition of dust to the DCC system under strong convection produces an initial burst of ice formation covering the range of the PSD. It is followed by a reduction in the small crystals and an increase in larger crystals and snow, as small crystals grow. This marks the transition from initial formation of small cloud ice into the regime dominated by particle interactions and collection, yielding larger particles. The liquid PSD describes enhancement to the largest drops resulting from non-freezing collection of small ice crystals and/or some degree of enhanced condensational growth in the stronger updrafts present. The greater presence of smaller drops is due to increased transport from below the freezing level, as the

10 small sizes limit the efficiency of freezing and collection. The middle size range of the liquid PSD is reduced though the duration of the simulation, corresponding with the enhanced population in the graupel PSD. The reduced liquid content is also a result of the more active Bergeron process. Occurrence frequency of grid cells with Bergeron process evaporation (not shown) increases up to $30 \%$, proportionally to IN number, between $5-7 \mathrm{~km}$ where ice formation is strongest and reduces to zero above this altitude as the cloud glaciates. The formation of graupel in our model occurs by two distinct mechanisms,

15 direct freezing of large liquid drops, by any freezing mechanism, and the interactions between liquid and ice. However, if the mass of one is small compared to the other, graupel will not be produced. For example, large liquid drops collecting small ice crystals without freezing or snow being rimed by small drops without a conversion into graupel. There is evidence of increased large drop freezing, as seen by the enhancement to the largest bin sizes in the graupel PSD, but the majority of these particles are being formed by riming as seen by the similar locations of reduction and enhancement between the liquid and graupel PSDs. The competition for available collection and vapor resources between the more numerous individual particles explains the progressive shift towards smaller bin sizes in the graupel distribution.

\subsection{PSD Vertical Profile and Sedimentation}

While the majority of ice and liquid hydrometeors are formed within the convective core, a significant amount of cloud mass is transported into the stratiform/anvil regime by upper level divergence and wind shear, where additional growth and particle collection may occur (Folkins, 2002; Mullendore, 2005). In addition, the actual contribution of the core to the total cloud area compared to the stratiform/anvil regime is small, at 1:7 (Liu and Fu, 2001) making consideration of dust effects on the stratiform regime important to the understanding of the large scale effects on the cloud fields reported in Min et al. (2009) and Min and Li (2010). The reflectivity measurements of Min et al. (2009) reported that dusty conditions reduced upper level reflectivity in convective clouds, while simultaneously increasing reflectivity at these levels in the stratiform clouds, compared to more pristine conditions. To rule out the effects of dynamics, profiles matching strong and weak convective events were compared in locations with minimal variation in aerosol loading and were found to produce upper level reflectivity values proportional to the convective strength in both convective and stratiform regimes, which supported the hypothesis that the effects of dust were microphysical rather than purely dynamical in nature. 
Atmos. Chem. Phys. Discuss., doi:10.5194/acp-2016-368, 2016

Manuscript under review for journal Atmos. Chem. Phys.

To examine the effects of microphysics on the convective and stratiform regime, Fig. 6 shows the time averaged vertical profile of bin PSD for the different hydrometeor species. Bin values in this figure are scaled the same as in Fig. 5, for readability purposes. The first column provides the Clean case convective average, while the second and third columns track the D1.2-Clean difference of convective and stratiform data, respectively. The Clean case's stratiform averages (not shown) possess a similar structure to the convective averages depicted in the first column, with bin concentrations about one order of magnitude lower. In both the convective and stratiform regimes, the upper level ice/snow PSD is narrowed, consistent with the observations of Min et al. (2009). The loss of the majority of small ice is a result of fewer small drops reaching the homogenous temperature range and subsequently freezing, while the reduction of larger aggregates is a result of increased competition between individual particles for available growth resources. The relative change in the stratiform regime is similar to the convective regime, although larger sized particles are more slightly common above the freezing level. The greater presence of large drops in Fig. 6f below the freezing level is consistent with larger particles melting. The presence of larger particles above the freezing level in the stratiform region is not simply a case of increased transport from the core, as we would expect a higher value in the convective data to co-locate with a lower value in the stratiform data as seen in the

15 maximum of small ice formation around $6 \mathrm{~km}$. Increased aggregation of particles after transport into the stratiform region would create a source of these larger sizes. This pattern of vertical distribution in Fig. 6 is also present in the D.12-Clean and D12-Clean PSD (not shown), varying mostly in absolute magnitude proportional to the total dust number.

Due to the effects of particle sedimentation, the location of the maximum values of number concentration for cloud and 20 precipitation particles may not reflect the location of original formation. This is especially true for precipitation particles which are heavier and more subject to gravitational settling. Considering the hydrometeor profiles separately before and after the effects of gravity have been applied allows for dust induced changes to cloud and precipitation processes to be tracked. Figure 7 shows the domain accumulated time series of "number flux" which is defined here as the instantaneous (pregravity) number subtracted from accumulated (post-gravity) number. Negative contour values represent locations of formation, while positive values represent the locations of final particle settling. Ice number (Fig. 7a-7d) tracks cloud ice formation, while snow (Fig. 7e-7h) and graupel (Fig. 7i-7l) number track changes to the precipitation forming processes of aggregation and riming, respectively. In the Clean case, the majority of significant ice formation occurs homogeneously during strong convection and settles just below the $-38^{\circ} \mathrm{C}$ isotherm, while snow formation occurs later when convection is weaker. Graupel formation location is not well defined in the Clean case due to the smaller mass of ice available for riming

30 in the heterogeneous regime. The higher dust numbers reduce the overall cloud ice numbers and shift greater amounts of the formation lower in the atmosphere as was noted in Fig. 4. The effects on the number flux of snow and graupel show clear evidence that the precipitation formation process begins earlier, with maximum values occurring higher in the atmosphere compared to less dusty conditions. The earlier formation of precipitation and reduced presence of small cloud ice explains 
Atmos. Chem. Phys. Discuss., doi:10.5194/acp-2016-368, 2016

Atmospheric

Chemistry

Published: 18 May 2016

(c) Author(s) 2016. CC-BY 3.0 License.

and Physics

Discussions

(c) (i)

the lower cloud top height despite the higher vertical motion present in the dust cases. This corresponds well with the theory of increased precipitation efficiency reducing anvil extent, as suggested in the study of Lindzen et al. (2001).

\subsection{Sensitivity to Particle Nucleation Characteristics}

The ice and liquid nucleating activity of any atmospheric aerosol particle is dependent on both its size and chemical

5 composition. Silicate dust is one of the most prominent IN in the atmosphere due to its significant concentration in the atmosphere (Prospero, 1999) and possession of favorable IN traits such as insolubility and crystallographic structure (Pruppacher and Klett, 1997). However it has also been reported that atmospheric processing, commonly termed 'aging' may leave a dust particle with a coating that impedes IN activity, by covering or destroying ice nucleating active sites (Tobo et al., 2012). It has also been reported that IN activity may only be significantly affected if the coating is chemically reactive

10 with the underlying particle (Wex et al., 2014). In the case of a soluble coating, dust particles may favor liquid nucleation over ice nucleation, their large size and soluble fraction allowing them to act as efficient CCN (Twohy et al., 2009). The presence of a soluble coating may also have an indirect effect on ice formation in liquid drop dependent freezing modes by depressing the freezing temperature of the drop due to added solute mass (Diehl and Wurzler, 2004). However, while soluble material is generally required for $\mathrm{CCN}$ activation, it has been established that an insoluble particle with little to no soluble

15 fraction may nucleate liquid drops under normal atmospheric conditions (Kumar et al., 2011; Karydis et al., 2013) allowing for dust to act as CCN with little effect on subsequent IN activity.

In order to better understand the sensitivity of ice microphysics to the balance between ice and liquid nucleating effects caused by the addition of dust to the environment, we have created a partition within the dust layer that changes the ratio of

20 IN to $\mathrm{CCN}$. This allows us to simulate differing dust particle nucleation characteristics in a simple way. As CCN activation in the model is dependent on both size and number, compared to IN activation which tracks number only, the fraction of dust treated as $\mathrm{CCN}$ is fit to the size distribution measured in the SAL by Chen et al. (2011) adjusted to match the selected CCN number concentration. For our primary dust cases (D.12; D1.2; D12) the dust partition is set to treat dust exclusively as IN with no CCN activation. Our justification for this being that Saharan dust tends to undergo less atmospheric processing than

25 Asian dust, which is exposed to greater levels of pollution (Fitzgerald et al., 2015). This suggests a much lower soluble fraction on the individual particles, minimizing CCN activity. As shown in previous figures, this IN only activation setting does allow for the model to reproduce similar large scale effects on the cloud field as those observed in Min et al. (2009) and Min and Li (2010). However, to provide an initial test of the MCS's sensitivity to different dust particle ice and liquid nucleation activity, we have run alternate simulations of the D1.2 (red line) case, shown in Fig. 8.

The first alternate case, D1.2b (orange line), total IN number remains the same, but does not contribute to depositioncondensation ice formation. The other ice and liquid formation methods remain unchanged from the base D1.2a case. This setup assumes that there is a factor, such as a coating, hindering access to the IN active sites until sufficient drop volume is 
Atmos. Chem. Phys. Discuss., doi:10.5194/acp-2016-368, 2016

Manuscript under review for journal Atmos. Chem. Phys.

Chemistry

Published: 18 May 2016

(c) Author(s) 2016. CC-BY 3.0 License.

and Physics

Discussions

(c) (i)

obtained and the effects of solute are minimized. The second alternate case, D1.2c (purple line), maintains the same total IN number and active ice formation methods, but adds $12.0 \mathrm{~cm}^{-3} \mathrm{CCN}$ to the dust layer. This allows for the effects of liquid nucleation occurring within the dust layer to be considered. The specific CCN number was chosen to coincide with the D12 case IN number and is the same order of magnitude of dust number $\left(\sim 30 \mathrm{~cm}^{-3}>0.5 \mathrm{um}\right)$ measured by the AEROSE study

5 (Morris et al., 2006). Fig. 8a and Fig. 8d describe the D1.2(a,b,c)-Clean case, time averaged, vertical profiles of convective ice/snow and cloud/rain drop number concentration, respectively. Outside of the clear increase of drop number in the vicinity of the dust layer, D1.2c produces a very similar profile of both ice and drop number, with slightly smaller reductions of liquid number $(7 \mathrm{~km})$ and subsequently ice number $(\sim 12 \mathrm{~km})$ due to additional available liquid content. The graupel number profile (not shown) is not significantly changed between the D1.2a and D1.2c cases. The corresponding time averaged bin

10 PSD covering the heterogeneous temperature range for ice/snow (Fig. 8b) and cloud/rain (Fig. 8e) shows similarly minor changes between the D1.2a and D1.2c and can be explained by the slightly higher starting liquid number. The small degree of these changes is to be expected, as the added dust CCN number, constrained by AEROSE observations, is small compared to the background $\mathrm{CCN}$ profile.

15 In contrast, the removal of deposition-condensation freezing has a significant effect on the number and PSD of both liquid and ice hydrometeors. Ice/snow number (Fig. 8a) and bin PSD (Fig. 8b) are reduced due to the smaller total ice formation, while liquid number is increased above the freezing level until immersion freezing peaks and the curve reverses. The smaller liquid number at temperatures above freezing can be explained by the reduced ice content immediately above the melting level. The liquid PSD (Fig. 8e) is enhanced by the reduced conversion of ice to liquid, with more competition between the

20 collecting drops shifting the size range slightly smaller. While ice multiplication is active in the D1.2b case, it does not compensate for the loss of small ice formed by the deposition-condensation scheme, subsequently delaying glaciation and reducing graupel formation until immersion freezing converts the large drops to graupel. Lawson et al. (2015) suggests that Hallett-Mossop ice multiplication is too limited to produce sufficient ice crystals to initiate rapid glaciation as opposed to the more vigorous drop shattering ice multiplication method used in that study. This may explain the reduced ice and graupel content in the D1.2b case despite the presence of other ice formation mechanisms.

We have established in Fig. 3 that higher IN concentrations will result in generally lower cloud top heights, but not the effect on total cloudiness over the entire vertical range of the atmosphere. Fig. 8c compares the cloudy pixel occurrence frequency of the Clean and various dust cases, with the primary Dust cases (D.12; D1.2; D12) showing a progressive increase in

30 midlevel cloudiness and reduced upper level cloudiness consistent with the increased heterogeneous ice formation and lowered cloud top height. The cloud occurrence frequency for the D1.2c case is virtually indistinguishable from the D1.2a base case, which is understandable considering the similarity between the hydrometeor and PSD profiles for the two cases. The D1.2b case exhibits the most distinct changes from the other Dust cases, due to the very different vertical profile of ice formation that occurred when deposition-condensation freezing was deactivated. Over most of the vertical range, the 
Atmos. Chem. Phys. Discuss., doi:10.5194/acp-2016-368, 2016

Manuscript under review for journal Atmos. Chem. Phys.

cloudiness percentage is between the Clean and D1.2a case values which can be explained by the reduced ice concentration being partially offset by a higher liquid drop number. The low cloudiness fraction around $12 \mathrm{~km}$ is reflected by the reduced ice number at that altitude. As cloud top height has a large effect on outgoing longwave radiation (OLR), Fig. $8 \mathrm{f}$ tracks the changes to OLR between the different cases. Lower cloud top heights result in higher OLR, consistent with the findings of

5 Min and $\operatorname{Li}(2010)$.

The choice of ice formation method has a strong impact on the subsequent ice formation and hydrometeor profile, as seen in

Fig. 8. The specific mechanism will determine the location and subsequent evolution of ice particles that form, with the earliest acting process affecting the remaining processes by changing the availability of resources. To examine the

10 interconnected nature, Fig. 9 describes the number fraction of ice activated by the individual ice schemes for the Clean and dust cases. In addition the total difference of each ice formation method is listed in Table 4 for each ice scheme. The difference values were created by summing over the domain and total model integration time for each case and subtracting from the appropriate Clean case values. Homogeneous activation (Fig. 9a) progressively reduces from a maximum in the Clean case to $0 \%$ in the D12 case, due to the lack of liquid drops transported to the $-38^{\circ} \mathrm{C}$ level. The percent changes of the 15 primary dust cases from the Clean case are: $-0.63 \%$ (D.12), $-64.7 \%$ (D1.2), and -99.8\% (D12). The D1.2c case with added $\mathrm{CCN}$ activation has a similar change to homogeneous activation (-57.6\%), but is slightly higher than the base D1.2a case. The D1.2b case, lacking the warmer range of ice formation provided by the deposition-condensation scheme, possesses a homogeneous activation fraction between the D.12 and other D1.2 cases (-80.1\%). While the D1.2b case possesses a greater drop number due to reduced particle riming, this is partially counteracted by increased immersion freezing. The deposition-

20 condensation (Fig. 9b) activation fraction likewise increases with increasing dust IN number from the minimum in the Clean case to the maximum in the D12 case, in all cases peaking at around $6 \mathrm{~km}$. The immersion/contact (Fig. 9c) activation fractions are combined as in the DeMott et al. (2015) scheme, due to the Muhlbauer and Lohmann (2009) contact scheme producing ice number concentration orders of magnitude lower than the others. The relative changes to immersion/contact activation in the dust cases from the Clean case are: $-39.2 \%$ (D.12), $-82.7 \%$ (D1.2a), $+11.7 \%$ (D1.2b), $-82.6 \%$ (D1.2c), and -

$2594.6 \%$ (D12).The immersion/contact number fraction is lower than the others and, counterintuitively, peaks with the Clean case despite that case's low IN number. This discrepancy can be explained by deposition-condensation activation peaking lower in the atmosphere compared to the immersion fraction, using up the available IN, and removing liquid drops by riming. The removal of deposition/condensation activation in the D1.2b case moves the maximum value to the location of the other cases' secondary peak $(\sim 10 \mathrm{~km})$. The strong effect of deposition-condensation freezing on ice formation both

30 individually and in combination with other mechanisms has also been noted in the study of Hiron and Flossman (2015), where significant midlevel $(5-6 \mathrm{~km})$ ice only formed when the deposition-condensation freezing mechanism was active. 
Atmos. Chem. Phys. Discuss., doi:10.5194/acp-2016-368, 2016

Manuscript under review for journal Atmos. Chem. Phys.

\section{Conclusions}

The case study of a MCS occurring on 08 March 2004 in the tropical eastern Atlantic, first described in Min et al. (2009) was simulated using the WRF model with a spectral-bin microphysical scheme in which ice nucleation parameters have been updated to connect with IN so that the effects of dust as IN can be explored. In the first of a two part study, we present the

5 effects of IN activation on ice formation processes and the eventual effects on the large-scale cloud fields. The hypothesis of Min et al. (2009) suggested that dust forming ice at heterogeneous temperature ranges resulted in changes to the precipitation formation processes and a large scale lowering of cloud top heights, despite the presence of convective invigoration, as evidenced by the increased presence of deep clouds with large IWP. Our simulations have reproduced the lowered cloud top heights and increased OLR as reported in Min and Li (2010), as well as the increased midlevel ice formation, and higher

10 total water content/path reported by Min et al. (2009). The counterintuitive changes to reflectivity profiles reported in the latter study, further expanded upon in $\mathrm{Li}$ and $\mathrm{Min}$ (2010), of reduced convective and increased stratiform reflectivity suggests that a closer consideration of the precipitation formation processes must be undertaken to better understand the feedbacks between dynamics and microphysics in DCC forming under dusty conditions. By forming more numerous ice crystals at warmer temperatures, the Dust cases initiate the precipitation forming processes of aggregation and riming earlier

15 in the simulation. This removes small hydrometeors by collection and, due to greater resource competition between the individual particles, reduces the formation of the largest hydrometeor sizes. The stronger updrafts resulting from enhanced ice growth transported a greater ice mass to the stratiform regime where additional growth and sedimentation occurred, producing the lowered cloud tops in our simulation and observed in Min and Li (2010).

20 While the IN number concentration has a strong effect on the vertical profile of ice number and mass, the specific mechanism of freezing is also of great importance to the resulting balance between liquid and ice hydrometeors and PSD. The formation of small ice at warmer temperatures affects the initiation of riming and affects the level of cloud glaciation, as seen when comparing the D1.2 cases with deposition-condensation freezing active and deactivated. While ice multiplication from the Hallett-Mossop scheme is active in both cases, removing the depositional-condensation nucleation is sufficient to

25 reduce graupel formation and delay the glaciation of the clouds until temperatures near the homogeneous freezing level where immersion freezing is most active. The observations/modeling studies of Lawson et al. (2015) and Ackerman et al. (2015) both suggest that this effect on cloud glaciation can be explained by sufficiently fast ice multiplication at warmer temperatures, creating small ice crystals similar to the effects of significantly large deposition-condensation freezing, although it should be noted that primary ice formation was not the focus of those studies and ice nucleation was treated

30 simply, leaving a possible gap in the understanding of the interactions between the ice nucleation and ice multiplication processes. In our simulation the removal of the deposition-condensation freezing greatly hinders the formation of midlevel ice, despite an unchanged IN concentration and active ice multiplication, showing the importance of even small number of midlevel ice formation to the overall vertical hydrometeor distribution. 
Atmos. Chem. Phys. Discuss., doi:10.5194/acp-2016-368, 2016

Manuscript under review for journal Atmos. Chem. Phys.

Chemistry

Published: 18 May 2016

(c) Author(s) 2016. CC-BY 3.0 License.

The formation of ice in the lower atmosphere has a strong effect on the intensity of vertical motion, due to latent heat release, as well as the eventual PSD of hydrometeors that form in the column. The more numerous particles allow for the particle interaction/collection related to ice phase precipitation formation to occur lower in the atmosphere and earlier in the simulation, delaying sedimentation and increasing vapor competition between particles, which in turn limits the maximum particle size. In the weaker updraft regime of the stratiform region, transported hydrometeors are able to grow more efficiently compared to the stronger updrafts of the convective region, an occurrence which has also been reported in the observations of Ackerman et al (2015). The reduced near surface reflectivity values observed by both Min et al. (2009) and $\mathrm{Li}$ and Min (2010) suggest that total surface precipitation will be affected by the effects of dusty conditions on cloud

10 dynamics and precipitation PSD, most likely resulting in an overall reduction in surface rain rates. In the second part of our study, we intend to more closely examine changes to the efficiency of the precipitation formation processes in the differing dynamical conditions of the convective and stratiform regimes when under the effects of dust aerosols.

\section{Acknowledgements}

This work was supported by the NSF under contract AGS-1138495, by US DOE's Atmospheric System Research program

15 (Office of Science, OBER) under contract DE-FG02-03ER63531, and by the NOAA Educational Partnership Program with Minority Serving Institutions (EPP/MSI) under cooperative agreements NA17AE1625 and NA17AE1623. J. Fan is supported by the U.S. Department of Energy (DOE) Atmospheric System Research (ASR) Program. The Pacific Northwest National Laboratory (PNNL) is operated for the DOE by Battelle Memorial Institute under contract DE-AC06-76RLO1830.

\section{References}

20 Ackerman, A. S., Fridlind, A. M., Grandin, A., Dezitter, F., Weber, M., Strapp, J. W., \& Korolev, A. V. (2015). High ice water content at low radar reflectivity near deep convection-Part 2: Evaluation of microphysical pathways in updraft parcel simulations. Atmospheric Chemistry and Physics, 15(20), 11729-11751.

Altaratz, O., Koren, I., Remer, L. A., \& Hirsch, E. (2014). Review: Cloud invigoration by aerosols—Coupling between microphysics and dynamics. Atmospheric Research, 140, 38-60.

Andreae, M. O., Rosenfeld, D., Artaxo, P., Costa, A. A., Frank, G. P., Longo, K. M., \& Silva-Dias, M. A. F. (2004). Smoking rain clouds over the Amazon. Science, 303(5662), 1337-1342. 
Atmos. Chem. Phys. Discuss., doi:10.5194/acp-2016-368, 2016

Manuscript under review for journal Atmos. Chem. Phys.

Published: 18 May 2016

(c) Author(s) 2016. CC-BY 3.0 License.

(c) (i)

Arakawa, A. (2004). The cumulus parameterization problem: Past, present, and future. Journal of Climate, 17(13), 24932525 .

Bigg, E. K. (1953). The formation of atmospheric ice crystals by the freezing of droplets. Quarterly Journal of the Royal 5 Meteorological Society, 79(342), 510-519.

Boucher, O., Randall, D., Artaxo, P., Bretherton, C., Feingold, G., Forster, P., ... \& Zhang, X. Y. (2013). Clouds and aerosols. In Climate change 2013: The physical science basis. Contribution of working group I to the fifth assessment report of the intergovernmental panel on climate change (pp. 571-657). Cambridge University Press.

10

Boucher, O., \& Quaas, J. (2013). Water vapour affects both rain and aerosol optical depth. Nature Geoscience, 6(1), 4-5.

Carlson, T. N., \& Prospero, J. M. (1972). The large-scale movement of Saharan air outbreaks over the northern equatorial Atlantic. Journal of Applied Meteorology, 11(2), 283-297.

15

Chen, G., Ziemba, L. D., Chu, D. A., Thornhill, K. L., Schuster, G. L., Winstead, E. L., ... \& Kooi, S. A. (2011). Observations of Saharan dust microphysical and optical properties from the Eastern Atlantic during NAMMA airborne field campaign. Atmospheric Chemistry and Physics, 11(2), 723-740.

20 Cotton, W. R., Tripoli, G. J., Rauber, R. M., \& Mulvihill, E. A. (1986). Numerical simulation of the effects of varying ice crystal nucleation rates and aggregation processes on orographic snowfall. Journal of climate and applied meteorology, 25(11), 1658-1680.

DeMott, P. J., Sassen, K., Poellot, M. R., Baumgardner, D., Rogers, D. C., Brooks, S. D., ... \& Kreidenweis, S. M. (2003).

25 African dust aerosols as atmospheric ice nuclei. Geophysical Research Letters, 30(14).

DeMott, P. J., Prenni, A. J., McMeeking, G. R., Sullivan, R. C., Petters, M. D., Tobo, Y., ... \& Kreidenweis, S. M. (2015). Integrating laboratory and field data to quantify the immersion freezing ice nucleation activity of mineral dust particles. Atmospheric Chemistry and Physics, 15(1), 393-409.

Devasthale, A., Krüger, O., \& Grassl, H. (2005). Change in cloud-top temperatures over Europe. Geoscience and Remote Sensing Letters, IEEE, 2(3), 333-336. 
Atmos. Chem. Phys. Discuss., doi:10.5194/acp-2016-368, 2016

Manuscript under review for journal Atmos. Chem. Phys.

Published: 18 May 2016

(C) Author(s) 2016. CC-BY 3.0 License.

(c) (i)
Atmospheric

Chemistry

and Physics

Discussions

Diehl, K., \& Wurzler, S. (2004). Heterogeneous drop freezing in the immersion mode: Model calculations considering soluble and insoluble particles in the drops. Journal of the atmospheric sciences, 61(16), 2063-2072.

Dunion, J. P., \& Velden, C. S. (2004). The impact of the Saharan air layer on Atlantic tropical cyclone activity. Bulletin of 5 the American Meteorological Society, 85(3), 353-365.

Dudhia, J. (1989). Numerical study of convection observed during the winter monsoon experiment using a mesoscale twodimensional model. Journal of the Atmospheric Sciences, 46(20), 3077-3107.

10 Ekman, A. M. L., Engström, A., \& Wang, C. (2007). The effect of aerosol composition and concentration on the development and anvil properties of a continental deep convective cloud. Quarterly Journal of the Royal Meteorological Society, 133(627), 1439-1452.

Fan, J., Zhang, R., Li, G., \& Tao, W. K. (2007). Effects of aerosols and relative humidity on cumulus clouds. Journal of

15 Geophysical Research: Atmospheres (1984-2012), 112(D14).

Fan, J., Ovtchinnikov, M., Comstock, J. M., McFarlane, S. A., \& Khain, A. (2009a). Ice formation in Arctic mixed-phase clouds: Insights from a 3-D cloud-resolving model with size-resolved aerosol and cloud microphysics. Journal of Geophysical Research: Atmospheres (1984-2012), 114(D4).

20

Fan, J., Yuan, T., Comstock, J. M., Ghan, S., Khain, A., Leung, L. R., ... \& Ovchinnikov, M. (2009b). Dominant role by vertical wind shear in regulating aerosol effects on deep convective clouds. Journal of Geophysical Research: Atmospheres (1984-2012), 114(D22).

25 Fan, J., Comstock, J. M., \& Ovchinnikov, M. (2010). The cloud condensation nuclei and ice nuclei effects on tropical anvil characteristics and water vapor of the tropical tropopause layer. Environmental Research Letters, 5(4), 044005.

Fan, J., Leung, L. R., Li, Z., Morrison, H., Chen, H., Zhou, Y., ... \& Wang, Y. (2012a). Aerosol impacts on clouds and precipitation in eastern China: Results from bin and bulk microphysics. Journal of Geophysical Research: Atmospheres (1984-2012), 117(D16).

30

Fan, J., Rosenfeld, D., Ding, Y., Leung, L. R., \& Li, Z. (2012). Potential aerosol indirect effects on atmospheric circulation and radiative forcing through deep convection. Geophysical Research Letters, 39(9). 
Atmos. Chem. Phys. Discuss., doi:10.5194/acp-2016-368, 2016

Manuscript under review for journal Atmos. Chem. Phys.

Published: 18 May 2016

(c) Author(s) 2016. CC-BY 3.0 License.

(c) (i)
Atmospheric

Chemistry

and Physics

Discussions

Fan, J., Leung, L. R., Rosenfeld, D., Chen, Q., Li, Z., Zhang, J., \& Yan, H. (2013). Microphysical effects determine macrophysical response for aerosol impacts on deep convective clouds. Proceedings of the National Academy of Sciences, 110(48), E4581-E4590.

5 Fan, J., Leung, L. R., DeMott, P. J., Comstock, J. M., Singh, B., Rosenfeld, D., ... \& Min, Q. (2014). Aerosol impacts on California winter clouds and precipitation during CalWater 2011: local pollution versus long-range transported dust. Atmospheric Chemistry and Physics, 14(1), 81-101.

Fitzgerald, E., Ault, A. P., Zauscher, M., Mayol-Bracero, O. L., \& Prather, K. A. (2015). Comparison of the mixing state of long-range transported Asian and African mineral dust. Atmospheric Environment.

Folkins, I. (2002). Origin of lapse rate changes in the upper tropical troposphere. Journal of the atmospheric sciences, 59(5), 992-1005.

15 Frederick, K. L. (2006). Anvil characteristics as seen by C-POL during the Tropical Warm Pool International Cloud Experiment (TWP-ICE) (Doctoral dissertation, Texas A\&M University).

Futyan, J. M., \& Del Genio, A. D. (2007). Deep convective system evolution over Africa and the tropical Atlantic. Journal of Climate, 20(20), 5041-5060.

20

Gong, W., Min, Q., Li, R., Teller, A., Joseph, E., \& Morris, V. (2010). Detailed cloud resolving model simulations of the impacts of Saharan air layer dust on tropical deep convection-Part 1: Dust acts as ice nuclei. Atmospheric Chemistry and Physics Discussions, 10(5), 12907-12952.

25 Halder, M., Hazra, A., Mukhopadhyay, P., \& Siingh, D. (2015). Effect of the better representation of the cloud icenucleation in WRF microphysics schemes: A case study of a severe storm in India. Atmospheric Research, 154, 155-174.

van den Heever, S. C., Carrió, G. G., Cotton, W. R., DeMott, P. J., \& Prenni, A. J. (2006). Impacts of nucleating aerosol on Florida storms. Part I: Mesoscale simulations. Journal of the atmospheric sciences, 63(7), 1752-1775.

Heymsfield, A. J., \& Miloshevich, L. M. (1993). Homogeneous ice nucleation and supercooled liquid water in orographic wave clouds. Journal of the Atmospheric Sciences, 50(15), 2335-2353. 
Atmos. Chem. Phys. Discuss., doi:10.5194/acp-2016-368, 2016

Manuscript under review for journal Atmos. Chem. Phys.

Published: 18 May 2016

(C) Author(s) 2016. CC-BY 3.0 License.

(c) (i)
Atmospheric

Chemistry

and Physics

Discussions

Hiron, T., \& Flossmann, A. I. (2015). A study of the role of the parameterization of heterogeneous ice nucleation for the modelling of microphysics and precipitation of a convective cloud. Journal of the Atmospheric Sciences, (2015).

Houze Jr, R. A. (1994). Cloud dynamics (Vol. 53). Academic press.

5

Igel, M. R., Drager, A. J., \& Heever, S. C. (2014). A CloudSat cloud object partitioning technique and assessment and integration of deep convective anvil sensitivities to sea surface temperature. Journal of Geophysical Research: Atmospheres, 119(17), 10515-10535.

10 Kain, J. S. (2004). The Kain-Fritsch convective parameterization: an update. Journal of Applied Meteorology, 43(1), 170181.

Karyampudi, V. M., \& Carlson, T. N. (1988). Analysis and numerical simulations of the Saharan air layer and its effect on easterly wave disturbances. Journal of the Atmospheric Sciences, 45(21), 3102-3136.

15

Karydis, V. A., Kumar, P., Barahona, D., Sokolik, I. N., \& Nenes, A. (2013). Assessing the Impact of Mineral Dust and Adsorption Activation on Cloud Droplet Formation. In Advances in Meteorology, Climatology and Atmospheric Physics (pp. 515-520). Springer Berlin Heidelberg.

20 Khain, A., Pokrovsky, A., Pinsky, M., Seifert, A., \& Phillips, V. (2004). Simulation of effects of atmospheric aerosols on deep turbulent convective clouds using a spectral microphysics mixed-phase cumulus cloud model. Part I: Model description and possible applications. Journal of the atmospheric sciences, 61(24), 2963-2982.

Khain, A., Pokrovsky, A., (2004). Simulation of effects of atmospheric aerosols on deep turbulent convective clouds using a

25 spectral microphysics mixed-phase cumulus cloud model Part II: Sensitivity study. Journal of the atmospheric sciences, 61(24), 2983-3001.

Khain, A., Rosenfeld, D., \& Pokrovsky, A. (2005). Aerosol impact on the dynamics and microphysics of deep convective clouds. Quarterly Journal of the Royal Meteorological Society, 131(611), 2639-2663.

30

Khain, A. P., BenMoshe, N., \& Pokrovsky, A. (2008). Factors determining the impact of aerosols on surface precipitation from clouds: An attempt at classification. Journal of the Atmospheric Sciences, 65(6), 1721-1748. 
Atmos. Chem. Phys. Discuss., doi:10.5194/acp-2016-368, 2016

Manuscript under review for journal Atmos. Chem. Phys.

Published: 18 May 2016

(C) Author(s) 2016. CC-BY 3.0 License.

(c) (i)
Atmospheric

Chemistry

and Physics

Discussions

Khain, A. P., Leung, L. R., Lynn, B., \& Ghan, S. (2009). Effects of aerosols on the dynamics and microphysics of squall lines simulated by spectral bin and bulk parameterization schemes. Journal of Geophysical Research: Atmospheres (19842012), 114(D22).

5 Khain, A., Lynn, B., \& Dudhia, J. (2010). Aerosol effects on intensity of landfalling hurricanes as seen from simulations with the WRF model with spectral bin microphysics. Journal of the Atmospheric Sciences, 67(2), 365-384.

Khain, A. P., Beheng, K. D., Heymsfield, A., Korolev, A., Krichak, S. O., Levin, Z., ... \& Heever, S. C. (2015). Representation of microphysical processes in cloud-resolving models: spectral (bin) microphysics vs. bulk parameterization.

Reviews of Geophysics.

Koren, I., Kaufman, Y. J., Rosenfeld, D., Remer, L. A., \& Rudich, Y. (2005). Aerosol invigoration and restructuring of Atlantic convective clouds. Geophysical Research Letters, 32(14).

15 Kumar, P., Sokolik, I. N., \& Nenes, A. (2011). Measurements of cloud condensation nuclei activity and droplet activation kinetics of fresh unprocessed regional dust samples and minerals. Atmospheric Chemistry and Physics, 11(7), 3527-3541.

Lawson, R. P., Woods, S., \& Morrison, H. (2015). The Microphysics of Ice and Precipitation Development in Tropical Cumulus Clouds. Journal of the Atmospheric Sciences, (2015).

20

Lee, S. S., Donner, L. J., Phillips, V. T., \& Ming, Y. (2008). The dependence of aerosol effects on clouds and precipitation on cloud-system organization, shear and stability. Journal of Geophysical Research: Atmospheres, 113(D16).

Lee, S. S., Donner, L. J., \& Penner, J. E. (2010). Thunderstorm and stratocumulus: how does their contrasting morphology affect their interactions with aerosols?. Atmospheric Chemistry and Physics, 10(14), 6819-6837.

Li, G., Wang, Y., \& Zhang, R. (2008). Implementation of a two-moment bulk microphysics scheme to the WRF model to investigate aerosol-cloud interaction. Journal of Geophysical Research: Atmospheres (1984-2012), 113(D15).

30 Li, R., \& Min, Q. L. (2010). Impacts of mineral dust on the vertical structure of precipitation. Journal of Geophysical Research: Atmospheres (1984-2012), 115(D9).

Li, R., Min, Q. L., \& Harrison, L. C. (2010). A case study: the indirect aerosol effects of mineral dust on warm clouds. Journal of the Atmospheric Sciences, 67(3), 805-816. 
Atmos. Chem. Phys. Discuss., doi:10.5194/acp-2016-368, 2016

Manuscript under review for journal Atmos. Chem. Phys.

Published: 18 May 2016

(c) Author(s) 2016. CC-BY 3.0 License.

(c) (i)
Atmospheric

Chemistry

and Physics

Discussions

Li, Z., Niu, F., Fan, J., Liu, Y., Rosenfeld, D., \& Ding, Y. (2011). Long-term impacts of aerosols on the vertical development of clouds and precipitation. Nature Geoscience, 4(12), 888-894.

5 Lindzen, R. S., Chou, M. D., \& Hou, A. Y. (2001). Does the earth have an adaptive infrared iris?. Bulletin of the American Meteorological Society, 82(3), 417-432.

Liu, G., \& Fu, Y. (2001). The characteristics of tropical precipitation profiles as inferred from satellite radar measurements.

気象集誌. 第 2 輯, 79(1), 131-143.

10

Liu, X., \& Penner, J. E. (2005). Ice nucleation parameterization for global models. Meteorologische Zeitschrift, 14(4), 499514.

Lohmann, U. (2002). Possible aerosol effects on ice clouds via contact nucleation. Journal of the atmospheric sciences, 15 59(3), 647-656.

Meyers, M. P., DeMott, P. J., \& Cotton, W. R. (1992). New primary ice-nucleation parameterizations in an explicit cloud model. Journal of Applied Meteorology, 31(7), 708-721.

20 Min, Q., \& Li, R. (2010). Longwave indirect effect of mineral dusts on ice clouds. Atmospheric Chemistry and Physics, 10(16), 7753-7761.

Min, Q. L., Li, R., Lin, B., Joseph, E., Wang, S., Hu, Y., ... \& Chang, F. (2009). Evidence of mineral dust altering cloud microphysics and precipitation. Atmospheric Chemistry and Physics, 9(9), 3223-3231.

25

Min, Q. L., Li, R., Lin, B., Joseph, E., Morris, V., Hu, Y., ... \& Wang, S. (2014). Impacts of mineral dust on ice clouds in tropical deep convection systems. Atmospheric Research, 143, 64-72.

Mlawer, E. J., Taubman, S. J., Brown, P. D., Iacono, M. J., \& Clough, S. A. (1997). Radiative transfer for inhomogeneous

30 atmospheres: RRTM, a validated correlated-k model for the longwave. Journal of Geophysical Research: Atmospheres (1984-2012), 102(D14), 16663-16682.

Morris, V., Clemente-Colón, P., Nalli, N. R., Joseph, E., Armstrong, R. A., Detrés, Y., ... \& Lumpkin, R. (2006). Measuring trans-Atlantic aerosol transport from Africa. Eos, Transactions American Geophysical Union, 87(50), 565-571. 
Atmos. Chem. Phys. Discuss., doi:10.5194/acp-2016-368, 2016

Manuscript under review for journal Atmos. Chem. Phys.

Published: 18 May 2016

(c) Author(s) 2016. CC-BY 3.0 License.

(c) (i)

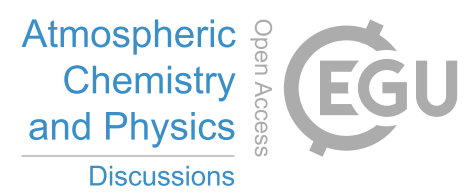

Muhlbauer, A., \& Lohmann, U. (2009). Sensitivity studies of aerosol-cloud interactions in mixed-phase orographic precipitation. Journal of the Atmospheric Sciences, 66(9), 2517-2538.

5 Mullendore, G. L., Durran, D. R., \& Holton, J. R. (2005). Cross-tropopause tracer transport in midlatitude convection. Journal of Geophysical Research: Atmospheres (1984-2012), 110(D6).

Nakanishi, M., \& Niino, H. (2006). An improved Mellor-Yamada level-3 model: Its numerical stability and application to a regional prediction of advection fog. Boundary-Layer Meteorology, 119(2), 397-407.

10

Niemand, M., Möhler, O., Vogel, B., Vogel, H., Hoose, C., Connolly, P., ... \& Leisner, T. (2012). A particle-surface-areabased parameterization of immersion freezing on desert dust particles. Journal of the Atmospheric Sciences, 69(10), 30773092 .

15 O'Dowd, C. D., Smith, M. H., Consterdine, I. E., \& Lowe, J. A. (1997). Marine aerosol, sea-salt, and the marine sulphur cycle: A short review. Atmospheric Environment, 31(1), 73-80.

Prospero, J. M. (1999). Long-term measurements of the transport of African mineral dust to the southeastern United States: Implications for regional air quality. Journal of Geophysical Research: Atmospheres (1984-2012), 104(D13), 15917-15927.

Prospero, J. M., \& Carlson, T. N. (1970). Radon-222 in the North Atlantic trade winds: Its relationship to dust transport from Africa. Science, 167(3920), 974-977.

Pruppacher, H. R., \& Klett, J. D. (1997). Microphysics of Clouds and Precipitation: With an Introduction to Cloud 25 Chemistry and Cloud Electricity, $954 \mathrm{pp}$.

Rosenfeld, D., Wood, R., Donner, L. J., \& Sherwood, S. C. (2013). Aerosol cloud-mediated radiative forcing: highly uncertain and opposite effects from shallow and deep clouds. In Climate Science for Serving Society (pp. 105-149). Springer Netherlands.

Sassen, K., DeMott, P. J., Prospero, J. M., \& Poellot, M. R. (2003). Saharan dust storms and indirect aerosol effects on clouds: CRYSTAL-FACE results. Geophysical Research Letters, 30(12). 
Atmos. Chem. Phys. Discuss., doi:10.5194/acp-2016-368, 2016

Skamarock, W. C., Klemp, J. B., Dudhia, J., Gill, D. O., Barker, D. M., Duda, M., ... \& Powers, J. G. A Description of the Advanced Research WRF Version 3 (2008) NCAR Technical Note. Boulder, CO.

Smirnova, T. G., Brown, J. M., \& Benjamin, S. G. (1997). Performance of different soil model configurations in simulating ground surface temperature and surface fluxes. Monthly Weather Review, 125(8), 1870-1884.

Solomon, S., Qin, D., Manning, M., Alley, R. B., Berntsen, T., Bindoff, N. L., ... \& Wratt, D. (2007). Technical summary.

Tao, W. K., Chen, J. P., Li, Z., Wang, C., \& Zhang, C. (2012). Impact of aerosols on convective clouds and precipitation. Reviews of Geophysics, 50(2).

10

Tobo, Y., DeMott, P. J., Raddatz, M., Niedermeier, D., Hartmann, S., Kreidenweis, S. M., ... \& Wex, H. (2012). Impacts of chemical reactivity on ice nucleation of kaolinite particles: A case study of levoglucosan and sulfuric acid. Geophysical Research Letters, 39(19).

15 Twohy, C. H., Kreidenweis, S. M., Eidhammer, T., Browell, E. V., Heymsfield, A. J., Bansemer, A. R., ... \& Van Den Heever, S. C. (2009). Saharan dust particles nucleate droplets in eastern Atlantic clouds. Geophysical Research Letters, $36(1)$.

Wex, H., DeMott, P. J., Tobo, Y., Hartmann, S., Rösch, M., Clauss, T., ... \& Stratmann, F. (2014). Kaolinite particles as ice 20 nuclei: learning from the use of different kaolinite samples and different coatings. Atmospheric Chemistry and Physics, 14(11), 5529-5546.

Yin, Y., Carslaw, K. S., \& Feingold, G. (2005). Vertical transport and processing of aerosols in a mixed-phase convective cloud and the feedback on cloud development. Quarterly Journal of the Royal Meteorological Society, 131(605), 221-245.

25

Yoon, Y. J., Ceburnis, D., Cavalli, F., Jourdan, O., Putaud, J. P., Facchini, M. C., ... \& O'Dowd, C. D. (2007). Seasonal characteristics of the physicochemical properties of North Atlantic marine atmospheric aerosols. Journal of Geophysical Research: Atmospheres (1984-2012), 112(D4).

30 Young, K. C. (1974). A numerical simulation of wintertime, orographic precipitation: Part I. Description of model microphysics and numerical techniques. Journal of the Atmospheric Sciences, 31(7), 1735-1748.

Zhang, D., \& Anthes, R. A. (1982). A high-resolution model of the planetary boundary layer-sensitivity tests and comparisons with SESAME-79 data. Journal of Applied Meteorology, 21(11), 1594-1609. 
Atmos. Chem. Phys. Discuss., doi:10.5194/acp-2016-368, 2016

Manuscript under review for journal Atmos. Chem. Phys.

Published: 18 May 2016

(C) Author(s) 2016. CC-BY 3.0 License.

\section{(c) (i)}

Atmospheric

Chemistry

and Physics

Discussions

Zhang, R., Li, G., Fan, J., Wu, D. L., \& Molina, M. J. (2007). Intensification of Pacific storm track linked to Asian pollution.

Proceedings of the National Academy of Sciences, 104(13), 5295-5299.

5 Zhang, R., Li, G., Fan, J., Wu, D. L., \& Molina, M. J. (2007). Intensification of Pacific storm track linked to Asian pollution.

Proceedings of the National Academy of Sciences, 104(13), 5295-5299.

\section{Tables}

Table 1

\begin{tabular}{|l|l|}
\hline \multicolumn{2}{|l|}{ Selected Weather Research and Forecasting (WRF) model parameterizations } \\
\hline Parameterization & Selected option \\
\hline Microphysics & $\begin{array}{l}\text { Domain 1,2,3: Thompson (Thompson et al., 2008); } \\
\text { Domain 4: SBM (cited in text) }\end{array}$ \\
\hline Cumulus & Domain 1,2: Kain-Fritsch (Kain, 2004) \\
\hline LW Radiation & Rapid Radiative Transfer Model (Mlawer et al., 1997) \\
\hline SW Radiation & Dudhia scheme (Dudhia, 1989) \\
\hline PBL & MYNN2(Nakanishi and Niino, 2006) \\
\hline Surface layer & MM5 similarity (Zhang and Anthes, 1982) \\
\hline Land surface & RUC LSM (Smirnova et al., 1997) \\
\hline
\end{tabular}

Table 2

\begin{tabular}{|l|l|l|l|l|l|l|l|}
\hline March 2004 Ship Observed Aerosol Number \\
\hline Radius & $0.3-0.5$ & $0.5-1$ & $1-5$ & $5-10$ & $10-25$ & 25 & micron \\
\hline Dust-free & 108.6 & 10.5 & 2.36 & 0.1029 & $3.00 \mathrm{E}-4$ & $5.50 \mathrm{E}-8$ & $\mathrm{~cm}^{-3}$ \\
\hline Dust & 87.32 & 34.7 & 7.557 & 0.3537 & $1.45 \mathrm{E}-3$ & $7.41 \mathrm{E}-6$ & $\mathrm{~cm}^{-3}$ \\
\hline
\end{tabular}

10 
Atmos. Chem. Phys. Discuss., doi:10.5194/acp-2016-368, 2016

Manuscript under review for journal Atmos. Chem. Phys.

Chemistry

Published: 18 May 2016

(c) Author(s) 2016. CC-BY 3.0 License.

and Physics

Discussions

(c) (1)

Table 3

\begin{tabular}{|c|c|c|c|c|c|c|}
\hline \multicolumn{7}{|c|}{ Average Dust Case Minus Clean Case Difference } \\
\hline \multirow{2}{*}{$\begin{array}{l}\text { Range } \\
\text { Case }\end{array}$} & \multicolumn{3}{|c|}{ Strong Convection (Hour 10-20) } & \multicolumn{3}{|c|}{ Weak Convection (Hour 20+) } \\
\hline & $D .12$ & D1.2 & D12 & $D .12$ & $\overline{D 1.2}$ & D12 \\
\hline Cloud Top & $-0.23 \mathrm{~km}$ & $-0.85 \mathrm{~km}$ & $-1.4 \mathrm{~km}$ & $-0.71 \mathrm{~km}$ & $-1.77 \mathrm{~km}$ & $-3.29 \mathrm{~km}$ \\
\hline Height & $(-2.0 \%)$ & $(-7.2 \%)$ & $(-11.7 \%)$ & $(-5.4 \%)$ & $(-13.3 \%)$ & $(-24.7 \%)$ \\
\hline Maximum & $+0.7 \mathrm{~m} / \mathrm{s}$ & $+1.5 \mathrm{~m} / \mathrm{s}$ & $+4.4 \mathrm{~m} / \mathrm{s}$ & $-0.6 \mathrm{~m} / \mathrm{s}$ & $-1.3 \mathrm{~m} / \mathrm{s}$ & $+1.6 \mathrm{~m} / \mathrm{s}$ \\
\hline Updraft & $(+4.8 \%)$ & $(+10.1 \%)$ & $(+29.8 \%)$ & $(-6.3 \%)$ & $(-14.2 \%)$ & $(+16.8 \%)$ \\
\hline Maximum & $+0.31 \mathrm{~m} / \mathrm{s}$ & $-0.75 \mathrm{~m} / \mathrm{s}$ & $-2.33 \mathrm{~m} / \mathrm{s}$ & $+0.09 \mathrm{~m} / \mathrm{s}$ & $+0.11 \mathrm{~m} / \mathrm{s}$ & $-0.73 \mathrm{~m} / \mathrm{s}$ \\
\hline Downdraft & $(-3.6 \%)$ & $(+21.1 \%)$ & $(+65.4 \%)$ & $(-3.3 \%)$ & $(-4.02 \%)$ & $(+26.6 \%)$ \\
\hline Homogeneous & $-38.3 \mathrm{~L}^{-1}$ & $-190.8 \mathrm{~L}^{-1}$ & $-200.4 \mathrm{~L}^{-1}$ & $-6.4 \mathrm{~L}^{-1}$ & $-36.3 \mathrm{~L}^{-1}$ & $-76.2 \mathrm{~L}^{-1}$ \\
\hline Ice Number & & & & & & \\
\hline Heterogeneous & $+1.7 \mathrm{~L}^{-1}$ & $+15.2 \mathrm{~L}^{-1}$ & $+83.0 \mathrm{~L}^{-1}$ & $+0.5 \mathrm{~L}^{-1}$ & $+2.2 \mathrm{~L}^{-1}$ & $+25.7 \mathrm{~L}^{-1}$ \\
\hline Ice Number & & & & & & \\
\hline Heterogeneous & $-1.31 \mathrm{~cm}^{-3}$ & $-2.77 \mathrm{~cm}^{-3}$ & $-3.49 \mathrm{~cm}^{-3}$ & $-0.27 \mathrm{~cm}^{-3}$ & $-0.63 \mathrm{~cm}^{-3}$ & $-0.95 \mathrm{~cm}^{-3}$ \\
\hline Drop Number & & & & & & \\
\hline Heterogeneous & $+1.3 \mathrm{~L}^{-1}$ & $+6.85 \mathrm{~L}^{-1}$ & $+17.24 \mathrm{~L}^{-1}$ & $+0.15 \mathrm{~L}^{-1}$ & $+1.37 \mathrm{~L}^{-1}$ & $+5.06 \mathrm{~L}^{-1}$ \\
\hline Graupel Number & & & & & & \\
\hline
\end{tabular}

Table 4

\begin{tabular}{|l|l|l|l|l|l|}
\hline \multicolumn{6}{|l|}{ Total Ice Formation Difference by Freezing Type } \\
\hline Case & $\mathbf{D . 1 2}$ & D1.2a & D1.2b & D1.2c & D12 \\
\hline Homogeneous $\left(\mathrm{cm}^{-3}\right)$ & -4.06 & -417.92 & -517.24 & -371.61 & -644.72 \\
& $(-0.63 \%)$ & $(-64.7 \%)$ & $(-80.1 \%)$ & $(-57.6 \%)$ & $(-99.8 \%)$ \\
\hline $\begin{array}{l}\text { Immersion/Contact } \\
\left(\mathrm{cm}^{-3}\right)\end{array}$ & -16.89 & -35.61 & +5.03 & -35.57 & -40.74 \\
\hline $\begin{array}{l}\text { Deposition- } \\
\text { condensation } \\
\left(\mathrm{cm}^{-3}\right)\end{array}$ & $(-39.2 \%)$ & $(-82.7 \%)$ & $(+11.7 \%)$ & $(-82.6 \%)$ & $(-94.6 \%)$ \\
\hline
\end{tabular}


Atmos. Chem. Phys. Discuss., doi:10.5194/acp-2016-368, 2016

Manuscript under review for journal Atmos. Chem. Phys.

Published: 18 May 2016

(c) Author(s) 2016. CC-BY 3.0 License.
Atmospheric

Chemistry

and Physics

\section{Figures}
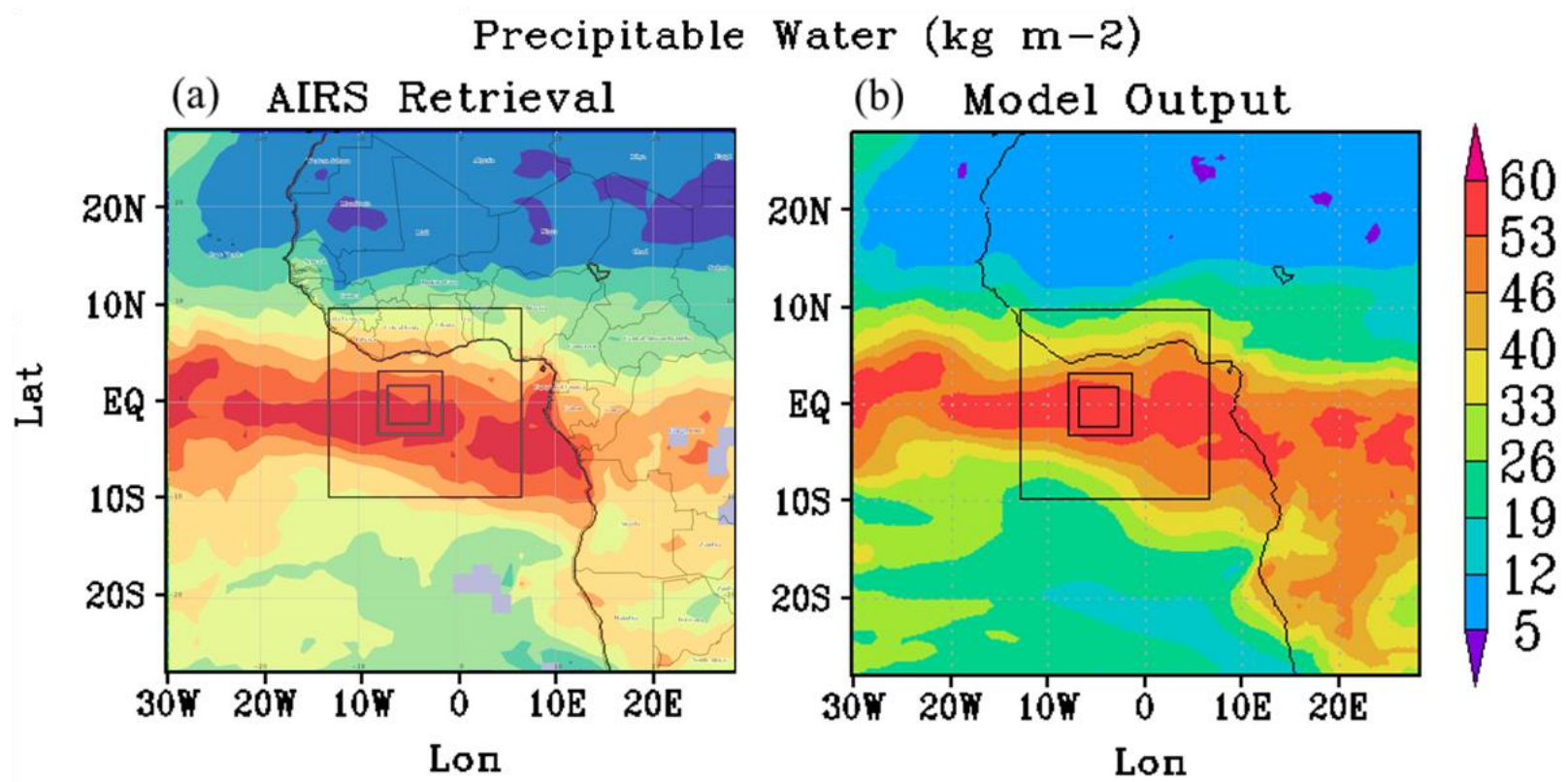

Figure 1: (a) AIRS total precipitable water averaged 07-09March2004, boxes denoting location of the three nested domains.

(b) Domain 1 model output precipitable water averaged 07-09March2004. 
Atmos. Chem. Phys. Discuss., doi:10.5194/acp-2016-368, 2016

Manuscript under review for journal Atmos. Chem. Phys.

Published: 18 May 2016

(C) Author(s) 2016. CC-BY 3.0 License.
Atmospheric

Chemistry

and Physics

Discussions

(c) (1)
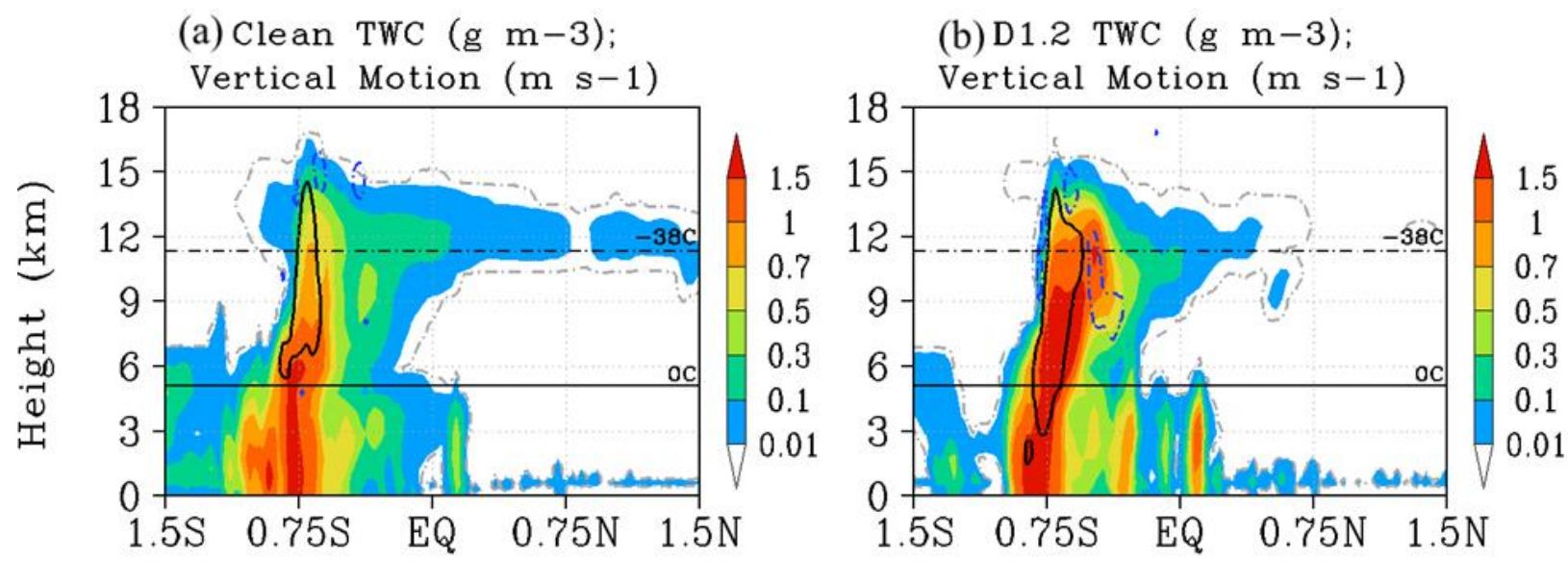

(c) Clean Rain Rate $(\mathrm{mm} \mathrm{h}-1)$;

(d) D1.2 Rain Rate ( $\mathrm{mm} \mathrm{h-1);}$
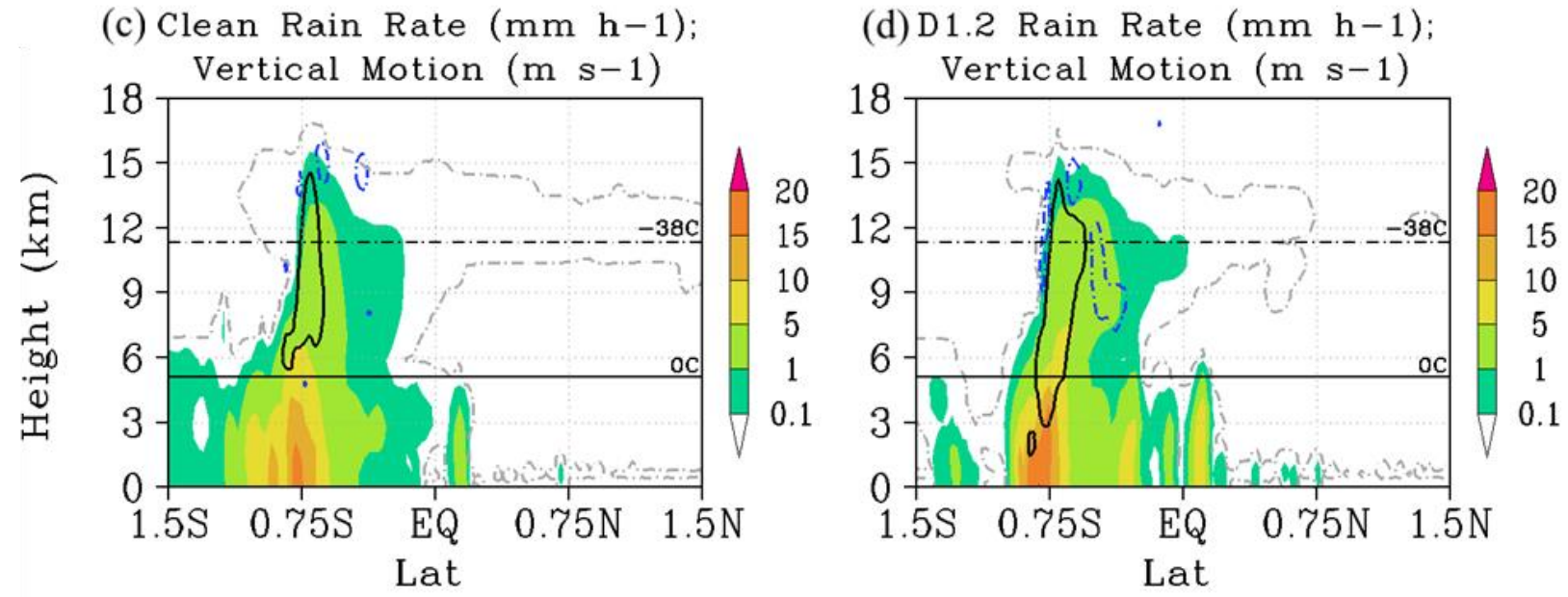

Figure 2: Vertical slice plots, in shaded colours, of: total water content (TWC; top row), and vertical rain rate (Bottom row); Line contours, all rows: vertical motion (solid black $>1 \mathrm{~m} / \mathrm{s}$; dashed blue <-0.1m/s). Columns: Clean (a,c), and D1.2 (b,d) cases. 
Atmos. Chem. Phys. Discuss., doi:10.5194/acp-2016-368, 2016

Manuscript under review for journal Atmos. Chem. Phys.

Published: 18 May 2016

(c) Author(s) 2016. CC-BY 3.0 License.
Atmospheric

Chemistry

and Physics

Discussions

(c) (1)
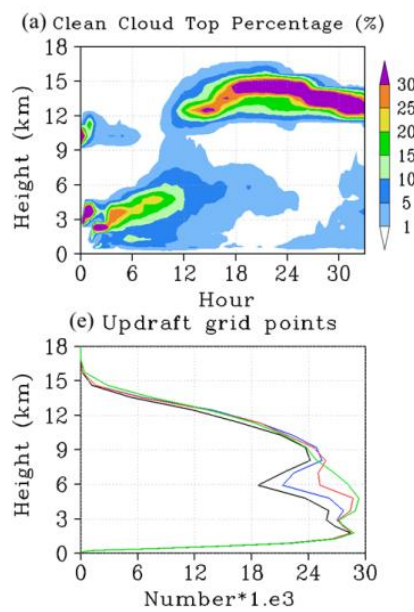

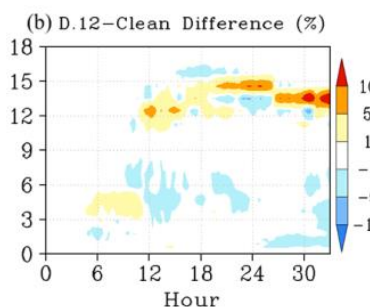

(f) (D.12) Vertical Motion

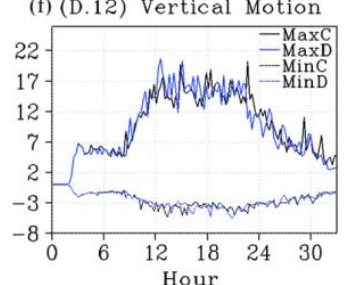

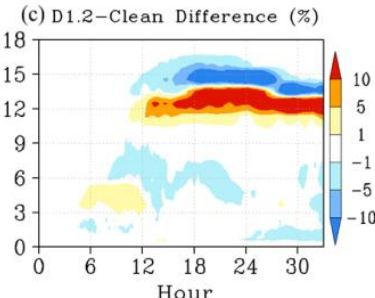

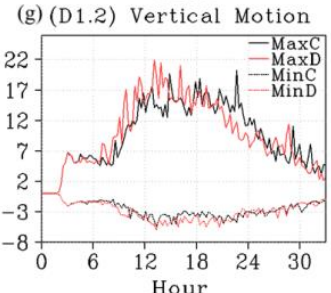

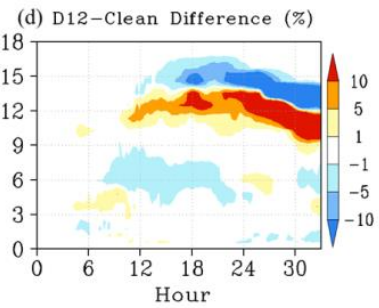

(h) (D12) Vertical Motion

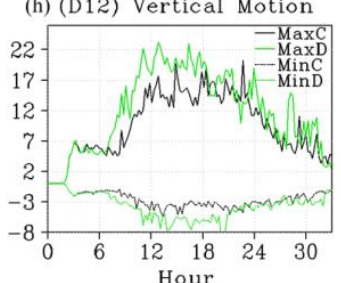

Figure 3: Top row: time series of percentage of cloud tops at the specified altitude for the (a) Clean and associated differences plots for the (b) D.12-Clean, (c) D1.2-Clean, and (c) D12-Clean cases. Bottom row: (e) total number of updraft grid points (>1m/s) w.r.t. height; time series of maximum domain vertical motion for the D.12 (f, blue), D1.2 (g, red), and D12 (h, green) cases compared to the Clean (black) case.
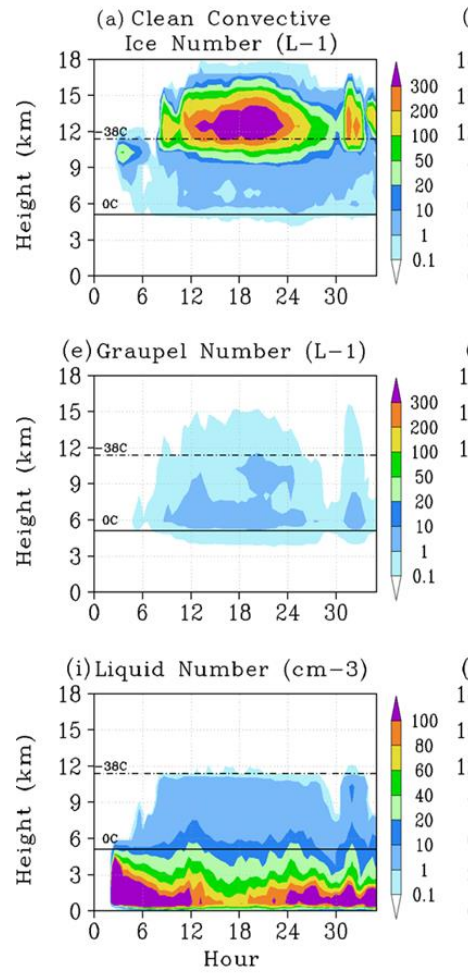
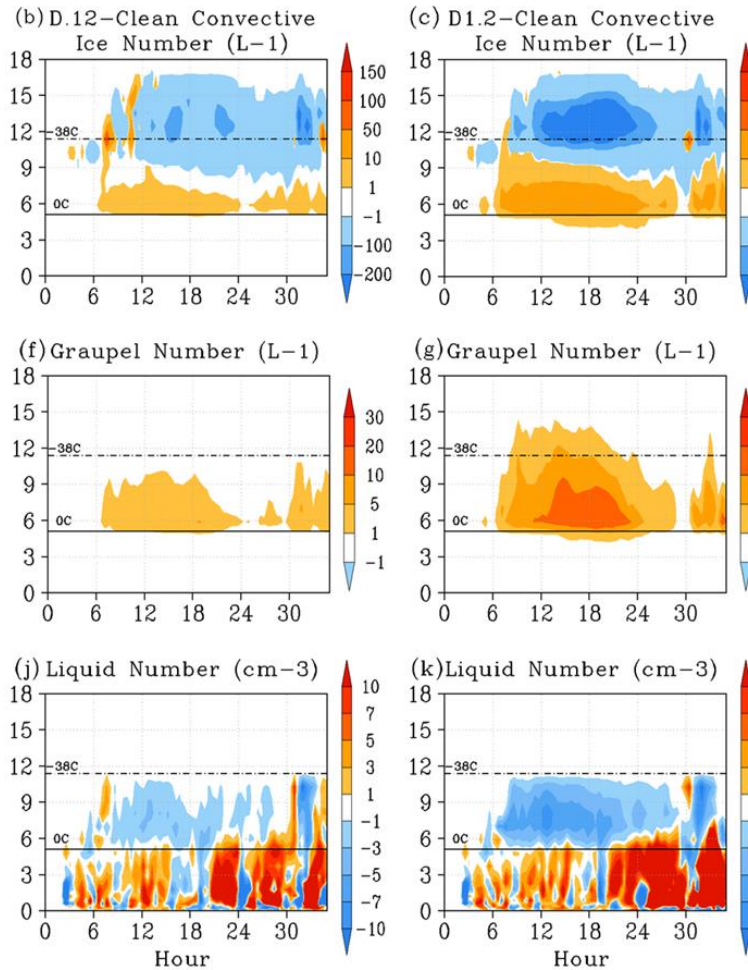
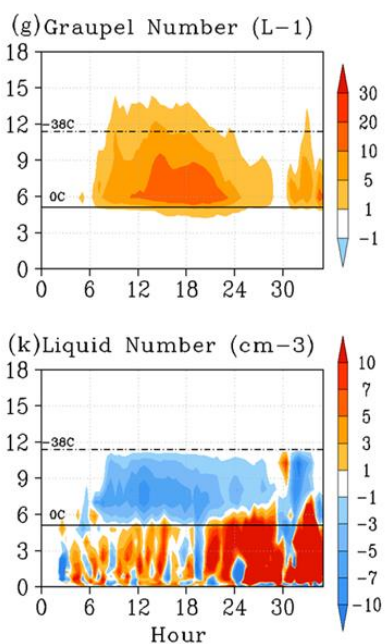
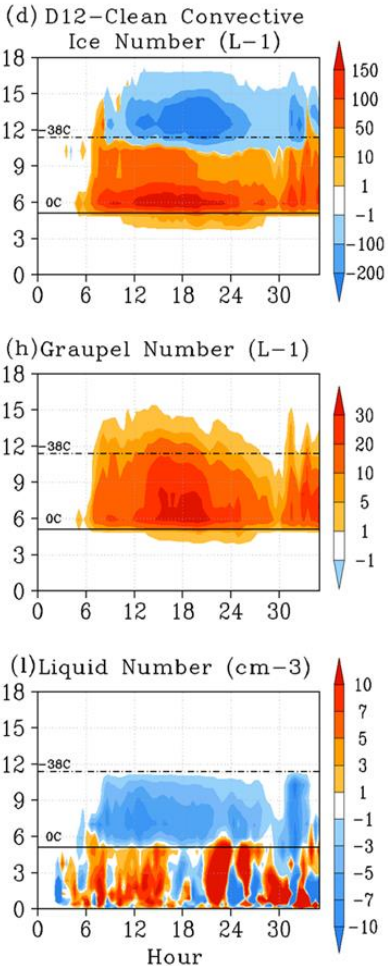
Atmos. Chem. Phys. Discuss., doi:10.5194/acp-2016-368, 2016

Manuscript under review for journal Atmos. Chem. Phys.

Published: 18 May 2016

(c) Author(s) 2016. CC-BY 3.0 License.
Atmospheric

Chemistry

and Physics

Discussions

(c) (i)

Figure 4: Convective averaged profiles and difference plots (Height vs time) of ice number concentration (top row), graupel number concentration (middle row), and liquid number concentration (Bottom row). Columns: Clean (a,e,i), D.12-Clean $(\mathrm{b}, \mathrm{f}, \mathrm{j})$, D1.2-Clean (c,g,k), and D12-Clean (d,h,l) cases.
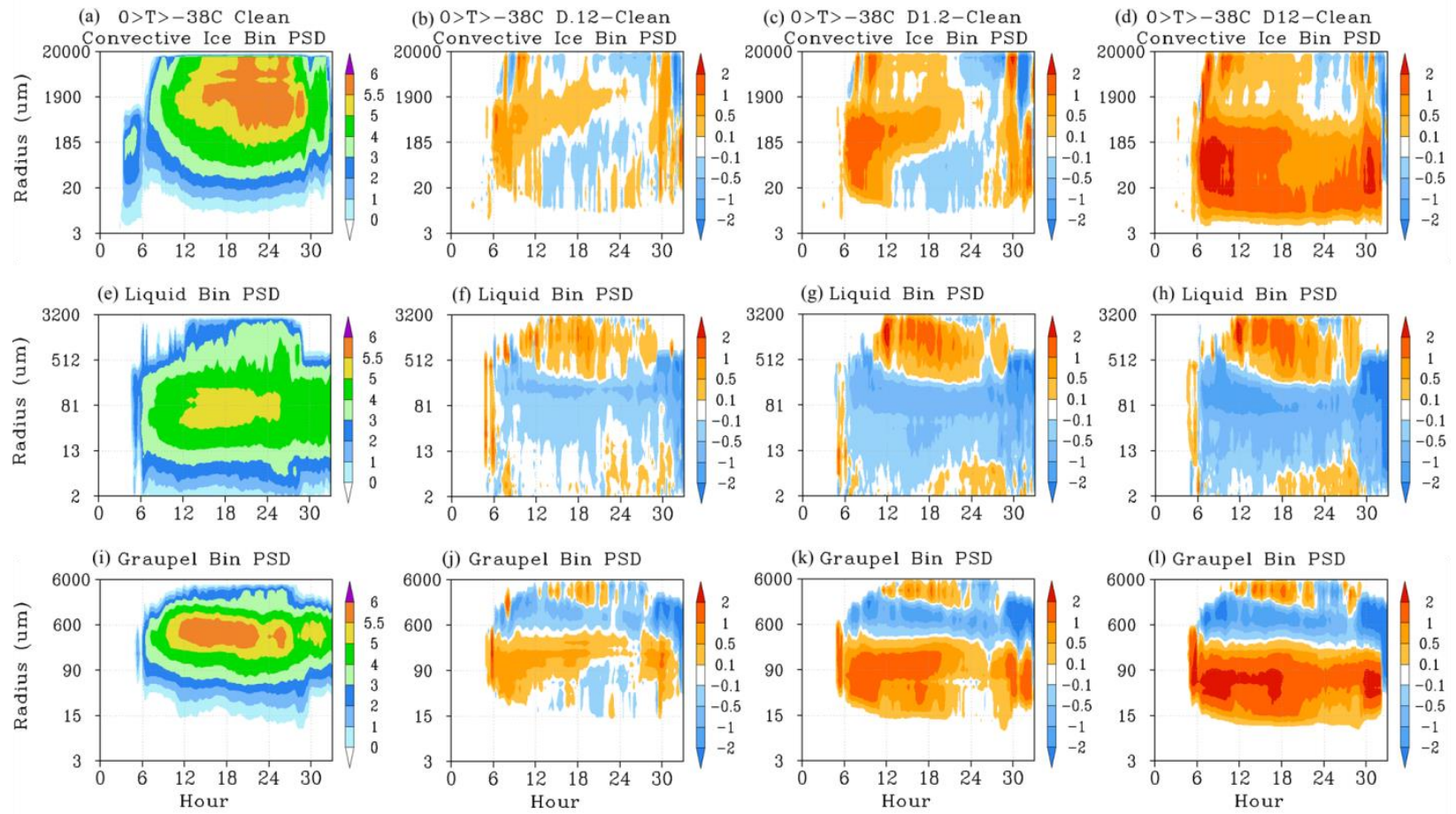

Figure 5: Time series and difference plots of: ice/snow bin particle size distribution (PSD; top row), graupel bin PSD (middle row), and liquid bin PSD (Bottom row); averaged over the convective regime at the temperature range of $0^{\circ} \mathrm{C}$ to $38^{\circ} \mathrm{C}$. Contours represent $10+\log 10$ values of bin population. Columns: Clean (a,e,i), D.12-Clean (b,f,j), D1.2-Clean (c,g,k), and D12-Clean (d,h,l) cases. 
Atmos. Chem. Phys. Discuss., doi:10.5194/acp-2016-368, 2016

Manuscript under review for journal Atmos. Chem. Phys.

Published: 18 May 2016

(C) Author(s) 2016. CC-BY 3.0 License.
Atmospheric

Chemistry

and Physics

Discussions

(c) (1)

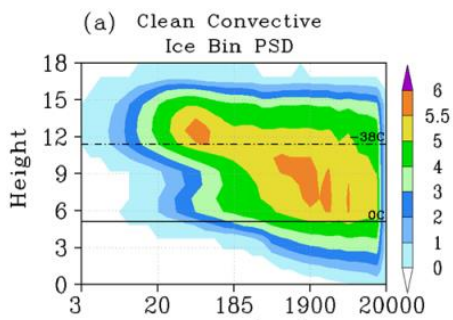

(b) D1.2-Clean Convective
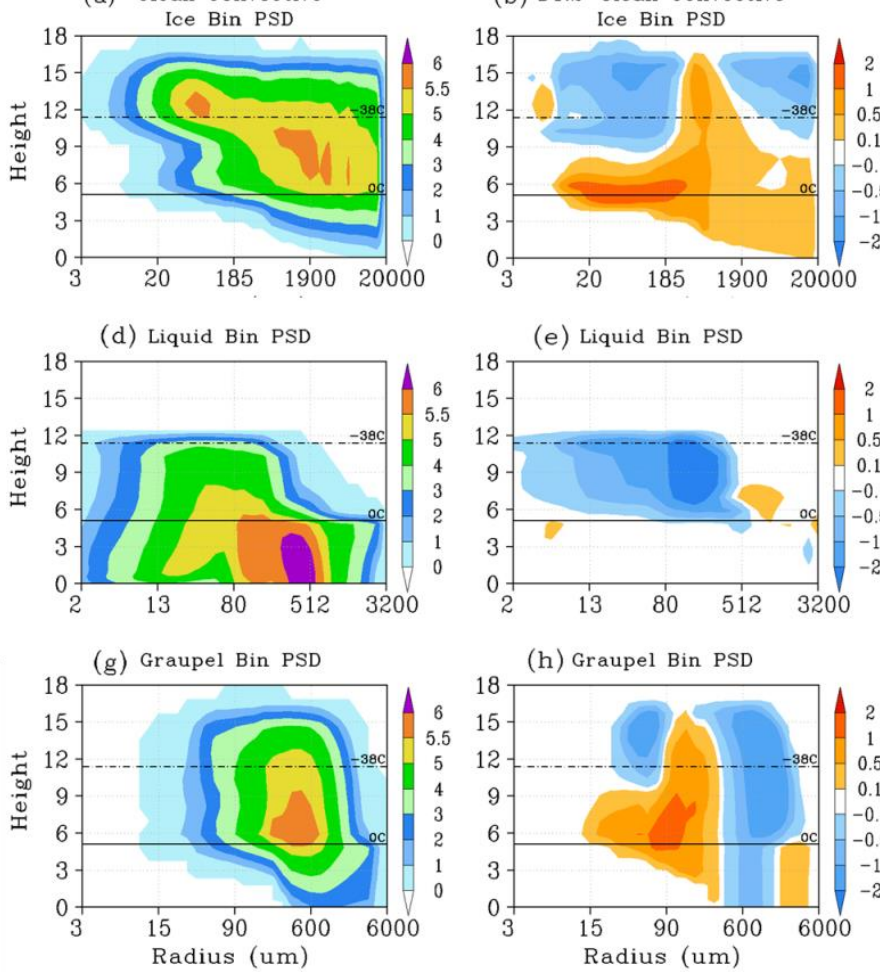

(e) Liquid Bin PSD
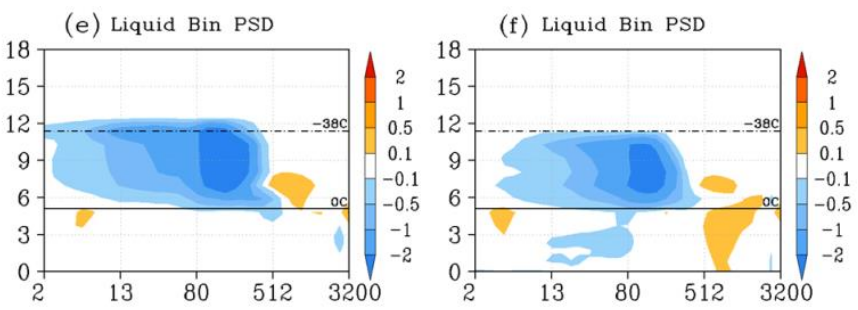

(h) Graupel Bin PSD

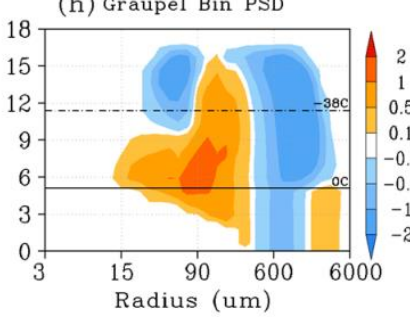

(c) D1.2-Clean Stratiform

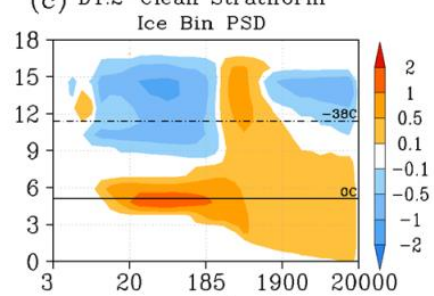

(i) Graupel Bin PSD

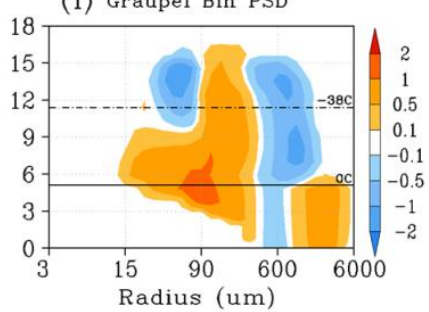

Figure 6: Time averaged vertical profile and difference plots of: ice bin PSD (top row), graupel bin PSD (middle row), and liquid bin PSD (Bottom row). Columns: Clean convective (a,d,g), D1.2-Clean convective (b,e,h), and D1.2-Clean stratiform $(\mathrm{c}, \mathrm{f}, \mathrm{i})$ averages. 
Atmos. Chem. Phys. Discuss., doi:10.5194/acp-2016-368, 2016

Manuscript under review for journal Atmos. Chem. Phys.

Published: 18 May 2016

(C) Author(s) 2016. CC-BY 3.0 License.
Atmospheric

Chemistry

and Physics

Discussions
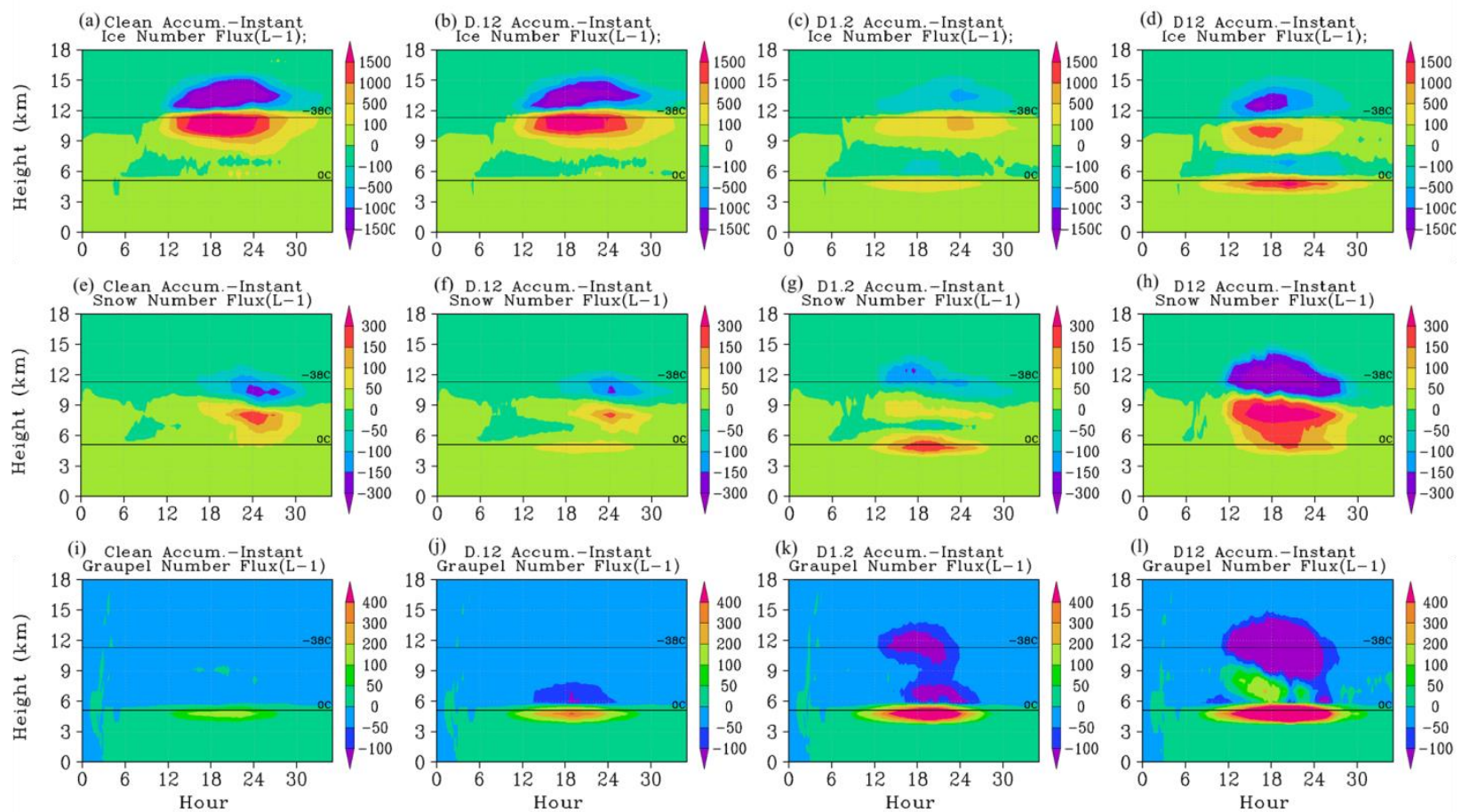

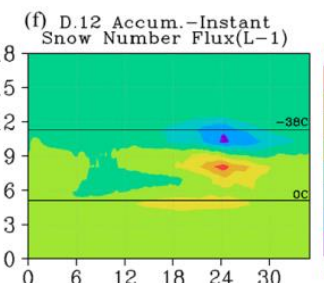

(j) D.12 Accum.- Instant
Graupel Number Flux (L-1)
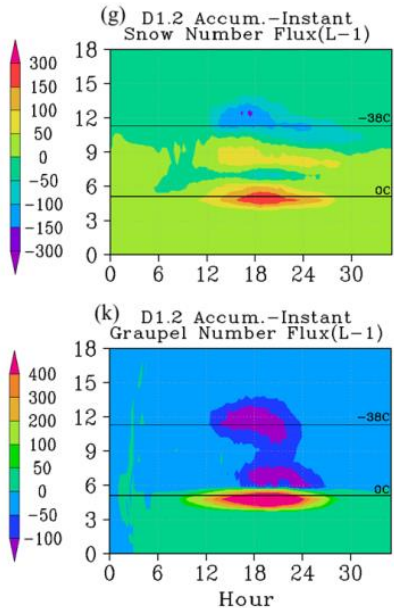

(h) D12 Accum. - Instant

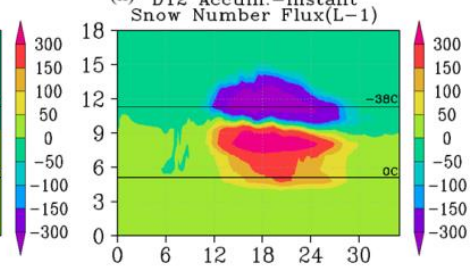

(l) D12 Accum. - Instant

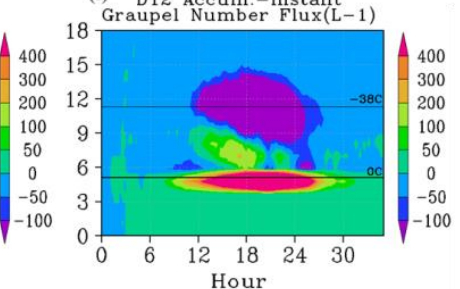

Figure 7: Domain accumulated time series plots of number concentration before (negative) and after (positive) gravitational settling for: cloud ice (top row), snow (middle row), and graupel (Bottom row). Columns: Clean (a,e,i), D.12 (b,f,j), D1.2 $(\mathrm{c}, \mathrm{g}, \mathrm{k})$, and D12 (d,h,l) cases.

(a) D1.2(a,b,c)-Clean Ice Number $(\mathrm{L}-1)$

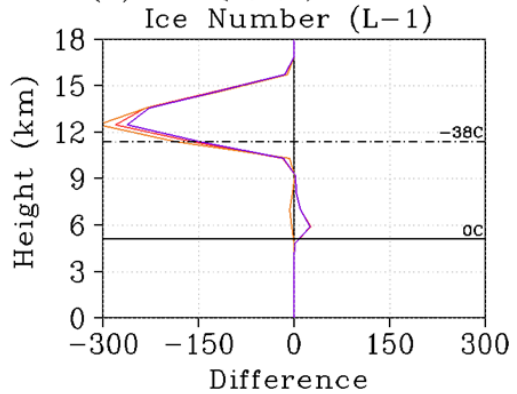

(d) Liquid Number $(\mathrm{cm}-3)$

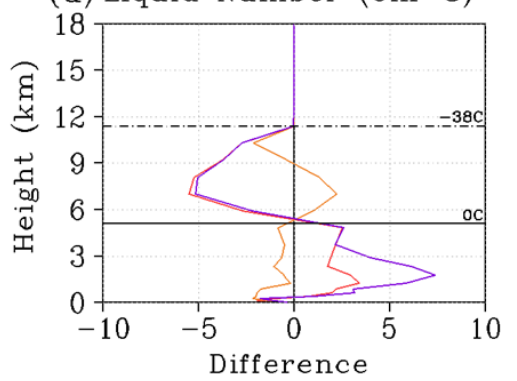

(b) $0>\mathrm{T}>-38 \mathrm{C}$ D1.2(a,b,c)-Clean

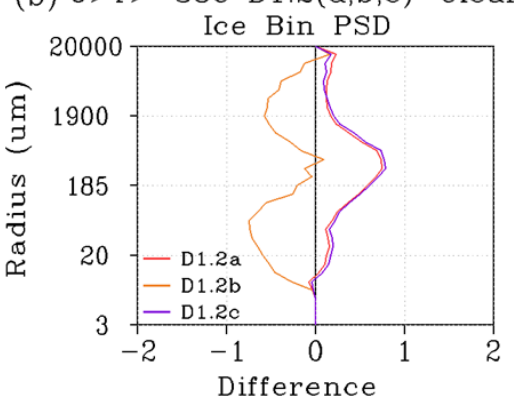

(e) Liquid Bin PSD

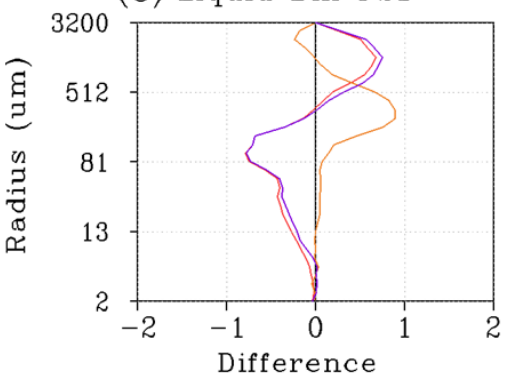

(c) Cloud Occurance

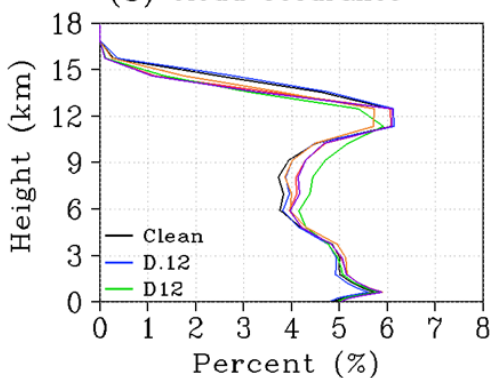

(f) Average OLR

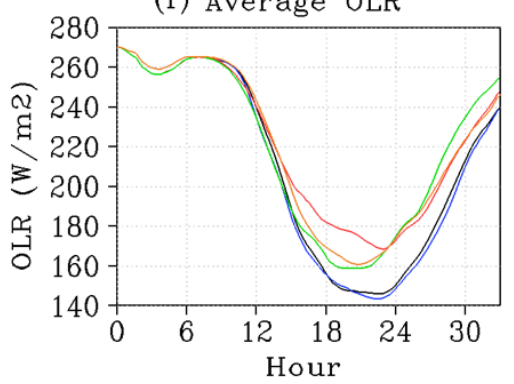


Atmos. Chem. Phys. Discuss., doi:10.5194/acp-2016-368, 2016

Manuscript under review for journal Atmos. Chem. Phys.

Published: 18 May 2016

(c) Author(s) 2016. CC-BY 3.0 License.

(c) (i)
Atmospheric

Chemistry

and Physics

Discussions

Figure 8: First column: alternate dust minus Clean case convective and time averaged ice (a) and liquid (d) number concentration for: D1.2a (original; red), D1.2b (no deposition; orange), and D1.2c (added CCN; purple). Second column: as first column for ice/snow (b) and cloud/rain (e) PSD averaged over the convective regime at the temperature range of $0^{\circ} \mathrm{C}$ to $-38^{\circ} \mathrm{C}$. Contours represent $10+\log 10$ values of bin population. Third column: cloudy pixel occurrence frequency (c) and time

5 series of domain averaged outgoing longwave radiation (OLR, f) for: Clean (black), D.12 (blue), D1.2a (red), D1.2b (orange), D1.2c (purple), and D12 (green) cases.
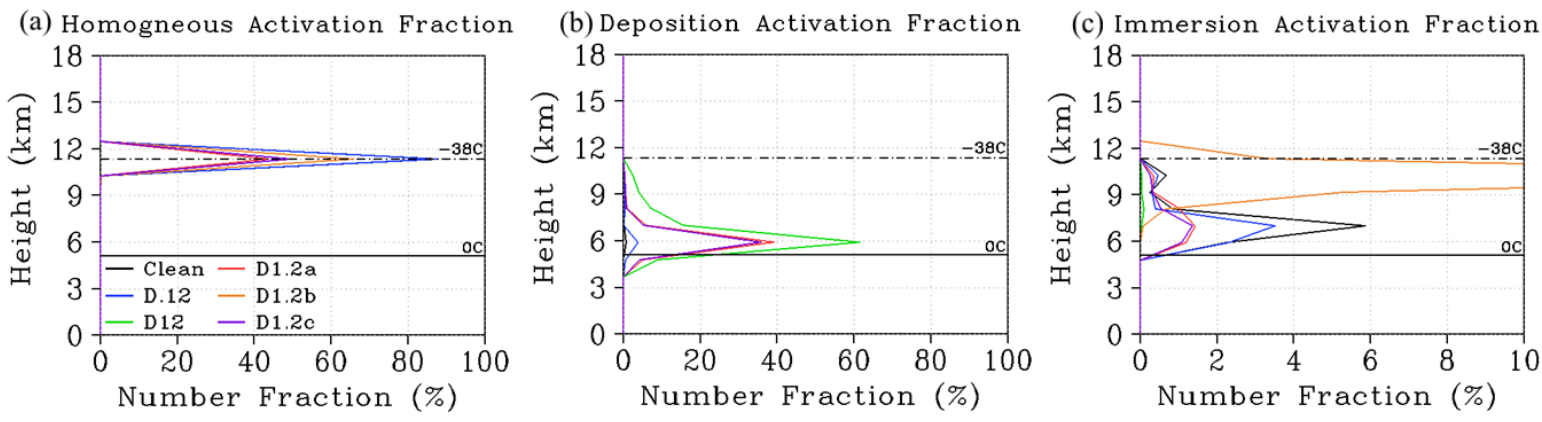

Figure 9: Number fraction of ice particles activated by (a) homogenous, (b) deposition-condensation, and (c) immersioncontact freezing schemes. Colors represent Clean (black), D.12 (blue), D1.2a (red), D1.2b (orange), D1.2c (purple) and D12 10 (green) cases, respectively. 